\title{
Adaptive Two-Stage Extended Kalman Filter Theory in Application of Sensorless Control for Permanent Magnet Synchronous Motor
}

\author{
Boyu Yi, ${ }^{1,2}$ Longyun Kang, ${ }^{1}$ Sinian Tao, ${ }^{1}$ Xianxian Zhao, ${ }^{1}$ and Zhaoxia Jing ${ }^{1}$ \\ ${ }^{1}$ School of Electric Power, South China University of Technology, Guangzhou, Guangdong 510640, China \\ ${ }^{2}$ Hunan Institute of Humanities Science and Technology, Loudi, Hunan 417000, China \\ Correspondence should be addressed to Longyun Kang; lykang@scut.edu.cn
}

Received 20 June 2013; Revised 26 September 2013; Accepted 17 October 2013

Academic Editor: Shihua Li

Copyright (C) 2013 Boyu Yi et al. This is an open access article distributed under the Creative Commons Attribution License, which permits unrestricted use, distribution, and reproduction in any medium, provided the original work is properly cited.

Extended Kalman filters (EKF) have been widely used for sensorless field oriented control (FOC) in permanent magnet synchronous motor (PMSM). The first key problem associated with EKF is that the estimator requires all the plant dynamics and noise processes are exactly known. To compensate inaccurate model information and improve tracking ability, adaptive fading extended Kalman filtering algorithms have been proposed for the nonlinear system. The second key problem is that the EKF suffers from computational burden and numerical problems when state dimension is large. The two-stage extended Kalman filter (TSEKF) with respect to this problem has been extensively studied in the past. Combining the advantages of both AFEKF and TSEKF, this paper presents an adaptive two-stage extended Kalman filter (ATEKF) for closed-loop position and speed estimation of a PMSM to achieve sensorless operation. Experimental results demonstrate that the proposed ATEKF algorithm for PMSMs has strong robustness against model uncertainties and very good real-time state tracking ability.

\section{Introduction}

Owing to their characteristics of high efficiency, high power density, and reliability, AC machines and more recently especially permanent magnet synchronous machines (PMSMs) have obtained dominance [1]. However, a PMSM cannot be easily controlled because of the uncertainties such as parameter variations and load-torque variations. Therefore, the linear-control methods such as PID control cannot guarantee high performance. To solve this problem, many researchers have proposed various design methods, for example, adaptive control $[2,3]$, robust control [4], sliding mode control [5], nonlinear feedback linearization control [6], and fuzzy control [7]. Recently, several authors [8-11] have proposed disturbance-observer-based PMSM control methods that can effectively suppress parameter variations or load-torque variations.

In most PMSM drives, some types of shaft sensors such as an optical encoder or a resolver are connected to the rotor shaft. However, such sensors cause several disadvantages such as high drive cost, low reliability, low noise immunity, and increase in machine size and maintenance requirements. Therefore, the interest toward sensorless FOC of PMSMs has grown in order to increase the reliability and to reduce the costs $[12,13]$.

Various methods of indirect (or sensorless) position and speed estimation have been investigated for PMSMs. One of major methods is based on extended Kalman filter (EKF) [1417]. The EKF is an optimal estimator in the least-square sense for estimating the states of dynamic nonlinear systems, and it is, thus, a viable and computationally efficient candidate for the online determination of rotor position and speed of a PMSM.

In spite of its successful use, extended Kalman filter still has some drawbacks. This extended Kalman filtering technique requires complete specifications of both dynamical model parameters and statistic noise levels of the system [18, 19]. In a number of practical situations, the models contain parameters that may deviate from their nominal values. The statistic noise levels of the model are given before the filtering 
process and will be maintained unchanged during the whole recursive process. Commonly, this a priori information is determined by test analysis and certain knowledge about the observation type beforehand. However, a priori information of this kind is often unavailable. Inaccuracy in system models or poor estimates of noise statistics may seriously degrade the performance of the filter and sometimes even leads to filtering divergence.

To overcome these drawbacks, several adaptive extended Kalman filtering algorithms have been proposed for the nonlinear system. Most of the work reported in this area has concentrated on innovation based adaptive estimation (IAE), which utilizes new statistical information from the innovation sequence to improve the estimation of the covariance matrices. IAE is originally proposed in [20] and later utilized in combination with fuzzy logic and neurofuzzy logic in $[21,22]$, for linear and nonlinear systems, respectively. One of the IAEs is called the adaptive fading extended Kalman filter (AFEKF) [23], which employs suboptimal fading factors. A weighting factor, which enhances the influence of innovation information, may be incorporated as a multiplier for improving the tracking capability in high dynamic control of PMSM.

On the other hand, Kalman filter (KF) appears to be very complex because of the high order of the mathematical models. The applicability of the KF to real-time state estimation problems is generally limited by the complex mathematical operations. To solve this problem, Friedland [24] proposed to employ the two-stage Kalman filter (TSKF) to decouple the $\mathrm{KF}$ into two parallel reduced-order filters. Many researchers $[25,26]$ have contributed to this problem. However, the results they obtained are suboptimal. The two-stage Kalman estimator in [27] can be optimal when satisfying an algebraic constraint, but almost all practical systems will not satisfy this algebraic constraint.

To improve the performance of TSKF, Hsieh and Chen propose an optimal two-stage kalman estimator (OTSKE) [28], in which the algebraic constraint [27] is removed and the optimal performance is guaranteed. OTSKE is mathematically equivalent to KF without requiring system constraints. Although the proposed OTSKE is slightly more complex than the TSKF, it prevents the performance degradation inherent in the TSKF. Therefore, the proposed OTSKE is the best balance between the performance and the computational complexity. It is known that many practical processes require nonlinear observers. In some works [29, 30], two-stage extended Kalman filter (TSEKF) has been developed by extending TSKF to nonlinear systems. In this paper, the structure of TSEKF will be employed in sensorless algorithm to reduce the computational complexity.

Combining advantages of TSEKF and AFEKF, we present an adaptive two-stage extended Kalman filter (ATEKF) for estimating rotor position and speed by the following twostep procedure: (1) in order to enhance robustness, astringency, and tracking ability, we introduce a fading factor into the conventional EKF to formulate AFEKF; (2) to solve the problem of computational complexity, an ATEKF is obtained based on proposed AFEKF algorithm. The proposed ATEKF is effective implementation of AFEKF. The complete equations of this filter are presented and compared with straight implementation of the AFEKF equations.

The paper is organized in six sections. In Section 2, according to the discrete model of the PMSM, a conventional EKF algorithm for estimating rotor position and speed is designed. In Section 3, an AFEKF is proposed, which uses the conventional EKF algorithm. In Section 4, ATEKF are developed by the same approach used for the OTSKE, and its stability is analyzed. In Section 5, to verify the performance of the ATEKF, experimental results are discussed. Finally, a conclusion wraps up the paper.

\section{Conventional EKF Theory}

2.1. The Model of PMSM. As elaborated in [6], the machine equations in the rotor $(d q)$ reference frame are as follows:

$$
\begin{gathered}
X_{k+1}=A_{k} X_{k}+B_{k}^{\Theta} \Theta_{k}+B_{k}^{u} U_{k}+W_{k}^{x}, \\
\Theta_{k+1}=G_{k} \Theta_{k}+W_{k}^{\Theta}, \\
Y_{k}=C_{k} X_{k}+\eta_{k},
\end{gathered}
$$

with

$$
\begin{aligned}
& X_{k}=\left[\begin{array}{ll}
i_{d} & i_{q}
\end{array}\right]^{T}, \quad \Theta_{k}=\left[\begin{array}{ll}
\omega_{r} & \theta_{r}
\end{array}\right]^{T}, \\
& U_{k}=\left[\begin{array}{ll}
u_{\alpha} & u_{\beta}
\end{array}\right]^{T}, \quad A_{k}=\left[\begin{array}{cc}
1-\frac{R_{s}}{L_{d}} T_{s} & \frac{\omega_{r} L_{q} T_{s}}{L_{d}} \\
-\frac{\omega_{r} L_{d} T_{s}}{L_{q}} & 1-\frac{R_{s}}{L_{q}} T_{s}
\end{array}\right] \text {, } \\
& Y_{k}=\left[\begin{array}{ll}
i_{\alpha} & i_{\beta}
\end{array}\right]^{T}, \quad B_{k}^{u}=\left[\begin{array}{cc}
\frac{\cos \theta_{r}}{L_{d}} T_{s} & \frac{\sin \theta_{r}}{L_{d}} T_{s} \\
-\frac{\sin \theta_{r}}{L_{q}} T_{s} & \frac{\cos \theta_{r}}{L_{q}} T_{s}
\end{array}\right] \text {, } \\
& G_{k}=\left[\begin{array}{cc}
1 & 0 \\
T_{s} & 1
\end{array}\right], \quad B_{k}^{\Theta}=\left[\begin{array}{cc}
0 & 0 \\
-\frac{\psi_{r} T_{s}}{L_{q}} & 0
\end{array}\right] \text {, } \\
& C_{k}=\left[\begin{array}{cc}
\cos \theta_{r} & -\sin \theta_{r} \\
\sin \theta_{r} & \cos \theta_{r}
\end{array}\right] \text {, }
\end{aligned}
$$

where $u_{\alpha}, u_{\beta}$ are the stator voltages in the $(\alpha \beta)$ reference frame, $i_{d}, i_{q}$ are stator flux currents in the $(d q)$ reference frame, $L_{d}$ and $L_{q}$ are the machine $d q$ axes inductances, $R_{s}$ is the stator winding resistance, and $\psi_{f}$ is the flux produced by the magnets. The angular velocity $\omega_{r}$ is measured in electrical radians per second. $\theta_{r}$ is the electrical position. $T_{s}$ is sampling period.

2.2. The EKF Algorithm. When treating $X_{k}$ as the full order state and $\Theta_{k}$ as the augmented system state, the state vector is chosen to be $X_{k}^{a}=\left[\begin{array}{ll}X_{k} & \Theta_{k}\end{array}\right]^{T} \cdot u_{\alpha}, u_{\beta}$ and $i_{\alpha}, i_{\beta}$ are chosen as input and output vectors because these quantities can be 
easily obtained from measurements of stator phase currents and voltage construction using DC link voltage and switching status. Considering the noise and parameter errors, the state space model in the rotor $(d q)$ reference frame is described by

$$
\begin{gathered}
X_{k+1}^{a}=\bar{A}_{k} X_{k}^{a}+\bar{B}_{k} U_{k}+W_{k}, \\
Y_{k+1}=\bar{C}_{k} X_{k}^{a}+\eta_{k},
\end{gathered}
$$

with

$$
\begin{array}{ll}
\bar{A}_{k}=\left[\begin{array}{cc}
A_{k} & B_{k}^{\Theta} \\
0 & G_{k}
\end{array}\right], & \bar{B}_{k}=\left[\begin{array}{c}
B_{k}^{u} \\
0
\end{array}\right], \\
\bar{C}_{k}=\left[\begin{array}{ll}
C_{k} & 0
\end{array}\right], & W_{k}=\left[\begin{array}{c}
W_{k}^{x} \\
W_{k}^{\Theta}
\end{array}\right],
\end{array}
$$

where $W_{k}$ and $\eta_{k}$ are zero-mean noise and are independent from the system state $X_{k}^{a}$. The system noise $W_{k}$ takes into account system disturbance and model inaccuracies, while $\eta_{k}$ represents the measurement noise. The noise covariance matrices are defined as follows:

$$
\begin{gathered}
E\left(W_{k}^{x}\left(W_{k-\tau}^{x}\right)^{T}\right)=Q_{k}^{x} \delta_{\tau}, \\
E\left(W_{k}^{\Theta}\left(W_{k-\tau}^{\Theta}\right)^{T}\right)=Q_{k}^{\Theta} \delta_{\tau}, \\
E\left(W_{k}^{x}\left(W_{k-\tau}^{\Theta}\right)^{T}\right)=Q_{k}^{x \Theta} \delta_{\tau}, \\
E\left(\eta_{k}\left(\eta_{k-\tau}\right)^{T}\right)=R_{k} \delta_{\tau}, \\
E\left(W_{k}^{x}\left(\eta_{k-\tau}\right)^{T}\right)=0, \\
E\left(W_{k}^{\Theta}\left(\eta_{k-\tau}\right)^{T}\right)=0 .
\end{gathered}
$$

Based on discretized machine equations, an EKF is constructed to estimate the rotor position and speed of the PMSM. The overall structure of the EKF is well known by employing a two-step prediction and correction algorithm [15]. The first step (prediction step) performs a prediction of both quantities based on the previous estimates $\widehat{X}_{k-1 \mid k-1}^{a}$ and the input vector $U_{k-1}$ actually applied to the system. The second step is the innovation step, correcting the predicted state estimation and its covariance matrix through a feedback correction gain $K_{k}$ that makes use of the actual measured quantities. Hence, the filter is given by

$$
\begin{gathered}
\widehat{X}_{k \mid k-1}^{a}=\bar{A}_{k-1} \widehat{X}_{k-1 \mid k-1}^{a}+\bar{B}_{k-1} U_{k-1}, \\
P_{k \mid k-1}=\bar{F}_{k-1} P_{k-1 \mid k-1} \bar{F}_{k-1}^{T}+Q_{k-1}, \\
K_{k}=P_{k \mid k-1} \bar{H}_{k}^{T}\left(\bar{H}_{k} P_{k \mid k-1} \bar{H}_{k}^{T}+R_{k}\right)^{-1}, \\
\widehat{X}_{k \mid k}^{a}=\widehat{X}_{k \mid k-1}^{\alpha}+K_{k}\left(Y_{k}-\bar{C}_{k} \widehat{X}_{k \mid k-1}^{a}\right), \\
P_{k \mid k}=P_{k \mid k-1}-K_{k} \bar{H}_{k} P_{k \mid k-1},
\end{gathered}
$$

with

$$
\begin{aligned}
& \widehat{X}_{k-1 \mid k-1}^{a}=\left[\begin{array}{llll}
i_{d} & i_{q} & \omega_{r} & \theta_{r}
\end{array}\right]^{T}, \\
& \bar{B}_{k-1}=\left[\begin{array}{c}
B_{k-1}^{u} \\
0
\end{array}\right], \quad \bar{A}_{k-1}=\left[\begin{array}{cc}
A_{k-1} & B_{k-1}^{\Theta} \\
0 & G_{k-1}
\end{array}\right] \text {, } \\
& \bar{F}_{k-1}=\left[\begin{array}{cc}
F_{k-1} & E_{k-1} \\
0 & G_{k-1}
\end{array}\right] \text {, } \\
& \bar{H}_{k}=\left[\begin{array}{ll}
H_{k}^{1} & H_{k}^{2}
\end{array}\right], \quad K_{k}=\left[\begin{array}{c}
K_{k}^{x} \\
K_{k}^{\Theta}
\end{array}\right] \text {, } \\
& F_{k-1}=\frac{\partial}{\partial X}\left(A_{k-1} X_{k-1}+B_{k-1}^{u} U_{k-1}+B_{k-1}^{\Theta} \Theta_{k-1}\right), \\
& E_{k-1}=\frac{\partial}{\partial \Theta}\left(A_{k-1} X_{k-1}+B_{k-1}^{u} U_{k-1}+B_{k-1}^{\Theta} \Theta_{k-1}\right), \\
& H_{k}^{1}=\frac{\partial}{\partial X}\left(C_{k-1} X_{k-1}\right), \quad \bar{C}_{k}=\left[\begin{array}{ll}
C_{k} & 0
\end{array}\right], \\
& H_{k}^{2}=\frac{\partial}{\partial \Theta}\left(C_{k-1} X_{k-1}\right), \quad P(\cdot)=\left[\begin{array}{cc}
P^{x}[\cdot] & P^{x \Theta}[\cdot] \\
P^{x \Theta}[\cdot]^{T} & P^{\Theta}[\cdot]
\end{array}\right], \\
& Q(\cdot)=\left[\begin{array}{cc}
Q^{x}[\cdot] & Q^{x \Theta}[\cdot] \\
Q^{x \Theta}[\cdot]^{T} & Q^{\Theta}[\cdot]
\end{array}\right] .
\end{aligned}
$$

\section{AFEKF Algorithm Based on Innovation Covariance Estimation}

Innovation of the filter, which is a directly observable parameter, can be used as a reference for the filter performance by observing the covariance of the innovation sequence. From the incoming measurement $Y_{k}$ and the optimal prediction $\widehat{X}_{k \mid k-1}^{a}$ obtained in the previous step, the innovation sequence is defined as

$$
\eta_{k}=Y_{k}-\bar{C}_{k} \widehat{X}_{k \mid k-1}^{a}
$$

Then, the innovation covariance of the EKF is

$$
\begin{aligned}
V_{k} & =E\left[\eta_{k} \eta_{k}^{T}\right] \\
& =E\left[\left(Y_{k}-\bar{C}_{k} \widehat{X}_{k \mid k-1}^{a}\right)\left(Y_{k}-\bar{C}_{k} \widehat{X}_{k \mid k-1}^{a}\right)^{T}\right] \\
& =\bar{H}_{k} P_{k+1 \mid k} \bar{H}_{k}^{T}+R_{k},
\end{aligned}
$$

where $V_{k}$ is referred to as the theoretical innovation covariance. Moreover, according to Shademan and Sharifi [31], an innovation covariance can be calculated by

$$
\bar{V}_{k}=\frac{1}{M-1} \sum_{i=k-M+1}^{k} \eta_{i} \eta_{i}^{T},
$$

where $M$ is a window size. This $\bar{V}_{k}$ is the estimated innovation covariance. 
If the system dynamic can be modeled exactly, the innovation of the filter should be a white noise sequence with zero mean. However, the statistical characteristics of the observed innovation sequence will become complex due to the fact that the prior knowledge of the process and measurement noise is not known exactly. This means that the theoretical error covariance $V_{k}$ is inconsistent with the estimated error covariance $\bar{V}_{k}$ in practical applications. We can use a scale factor to weigh the relation between $V_{k}$ and $\bar{V}_{k}$. This factor is defined as $\bar{V}_{k}=\alpha_{k} V_{k}$. Then, the scalar variable $\alpha_{k}$ can be estimated by

$$
\alpha_{k}=\max \left\{1, \frac{1}{m} \operatorname{tr}\left(\bar{V}_{k} V_{k}^{-1}\right)\right\} .
$$

Considering complexity of matrix inversion, the above equation can be replaced by

$$
\alpha_{k}=\max \left\{1, \frac{\operatorname{tr}\left(\bar{V}_{k}\right)}{\operatorname{tr}\left(V_{k}\right)}\right\} .
$$

In order to compensate the effect of unmodeled dynamic, the approach envisaged by the fading memory is based on applying a scale factor $\lambda_{k}$ to the a priori estimate error covariance to deliberately increase the variance of the predicted state vector, thus resulting in more "weight" given to the actual measurements. Thus, when the innovation covariance is increased by unaccounted errors, the increased predicted error covariance $\bar{P}_{k \mid k-1}$ can be utilized to compensate the effect of an inexact dynamic equation. $\bar{P}_{k \mid k-1}$ is obtained by

$$
\bar{P}_{k \mid k-1}=\lambda_{k} P_{k \mid k-1} \text {. }
$$

Here, the scale factor $\lambda_{k}$ is called a fading factor and $\lambda_{k} \geq 1$. Different fading memory approaches employ several algorithms to calculate the fading factor. One simple approach is to assign the fading factor as a constant, but this leads to some drawbacks. In this paper, we propose a fading memory algorithm using a variable fading factor that will be determined based on the innovation sequence associated with the dynamic and observation model accuracy. According to the above analysis, $\bar{V}_{k}$ can be represented by

$$
\begin{aligned}
\bar{V}_{k} & =\bar{H}_{k} P_{k+1 \mid k} \bar{H}_{k}^{T}+R_{k} \\
& =\bar{H}_{k}\left(\lambda_{k} P_{k \mid k-1}\right) \bar{H}_{k}^{T}+R_{k}
\end{aligned}
$$

or

$$
\begin{aligned}
\bar{V}_{k} & =\alpha_{k} V_{k} \\
& =\alpha_{k}\left(\bar{H}_{k} P_{k+1 \mid k} \bar{H}_{k}^{T}+R_{k}\right) .
\end{aligned}
$$

In (18), we can obtain the following equations:

$$
\bar{H}_{k}\left(\lambda_{k} P_{k \mid k-1}\right) \bar{H}_{k}^{T}+R_{k}=\alpha_{k}\left(\bar{H}_{k} P_{k+1 \mid k} \bar{H}_{k}^{T}+R_{k}\right) .
$$

Then $\lambda_{k}$ can be approximated by the following equation:

$$
\lambda_{k} \approx \frac{\operatorname{tr}\left(\alpha_{k} \bar{H}_{k} P_{k \mid k-1} \bar{H}_{k}^{T}+\left(\alpha_{k}-1\right) R_{k}\right)}{\operatorname{tr}\left(\bar{H}_{k} P_{k \mid k-1} \bar{H}_{k}^{T}\right)} .
$$

It can be inferred from (3) that time-varying motor parameters, such as stator resistance and inductance, are not included in (3). This means that the measurement dynamic equation does not have unaccounted errors. So the innovation covariance is mainly affected by predicted error covariance not by the measurement covariance. Therefore, the ratio of innovation covariances $\lambda_{k}$ is mainly determined by $\alpha_{k}$. In this paper, our hypothesis is that $\alpha_{k}$ is equal to $\lambda_{k}$; then the ratio between the error covariance can be replaced by $\alpha_{k}$. Thus, (7) in conventional EKF can be rewritten as follows to build AFEKF by employing the multiplier $\lambda_{k}$ :

$$
P_{k \mid k-1}=\lambda_{k}\left(\bar{F}_{k-1} P_{k-1 \mid k-1} \bar{F}_{k-1}^{T}+Q_{k-1}\right) \text {. }
$$

As stated in [32], this type of AEKF is called as "the AFEKF with rescaling- $P_{k \mid k-1}$." Compared to the proposed adaptive algorithms with excessive computational load in $[21,22]$, the AFEKF with rescaling- $P_{k \mid k-1}$ is simple and easy to realize.

\section{The Adaptive Two-Stage Extended Kalman Filter}

4.1. The ATEKF Algorithm. Following the same coordinate transformation as used in OTSKE [28], the ATEKF is obtained by decoupling AFEKF into two parallel filters: one for full order states and another one for the augmented states. So it is necessary to define a transformation matrix $T(\cdot)$, and $T(\cdot)$ is specified as follows:

$$
T(J)=\left[\begin{array}{ll}
I & J \\
0 & I
\end{array}\right] .
$$

The main advantage of using the $T$ transformation is that the inverse transformation $T^{-1}(M)=T(-M)$ involves only a change of sign. Two blending matrices $M_{k}$ and $N_{k}$ are defined, respectively, by $M_{k}=P_{k \mid k-1}^{x \Theta}\left(P_{k \mid k-1}^{\Theta}\right)^{-1}$ and $N_{k}=$ $P_{k \mid k}^{x \Theta}\left(P_{k \mid k}^{\Theta}\right)^{-1}$. The transformation operation can be achieved by two transformation matrices $T\left(M_{k}\right)$ and $T\left(N_{k}\right)$ so that the variance-covariance matrices $\bar{P}(\cdot)$ in new base are block diagonal:

$$
\bar{P}(\cdot)=\left[\begin{array}{cc}
\bar{P}^{x}(\cdot) & 0 \\
0 & \bar{P}^{\Theta}(\cdot)
\end{array}\right] .
$$

Using the two transformation matrices defined above, overlined expressions that correspond to vectors and matrices in the new base can be obtained:

$$
\begin{gathered}
X_{k \mid k-1}^{a}=T\left(M_{k}\right) \bar{X}_{k \mid k-1}^{a}, \\
P_{k \mid k-1}=T\left(M_{k}\right) \bar{P}_{k \mid k-1} T\left(M_{k}\right)^{T}, \\
X_{k \mid k}^{a}=T\left(N_{k}\right) \bar{X}_{k \mid k}^{a}, \\
K_{k}=T\left(N_{k}\right) \bar{K}_{k}, \\
P_{k \mid k}=T\left(N_{k}\right) \bar{P}_{k \mid k} T\left(N_{k}\right)^{T},
\end{gathered}
$$


where

$$
\bar{X}_{k}^{a}=\left[\begin{array}{l}
\bar{X}_{k} \\
\bar{\Theta}_{k}
\end{array}\right], \quad \bar{K}_{k}=\left[\begin{array}{c}
\bar{K}_{k}^{x} \\
\bar{K}_{k}^{\Theta}
\end{array}\right] .
$$

So the following relations are obtained:

$$
\begin{gathered}
P_{k \mid k-1}^{x}=\bar{P}_{k \mid k-1}^{x}+M_{k} \bar{P}_{k \mid k-1}^{\Theta} M_{k}^{T}, \\
P_{k \mid k-1}^{\Theta}=\bar{P}_{k \mid k-1}^{\Theta}, \\
P_{k \mid k-1}^{x \Theta}=M_{k} \bar{P}_{k \mid k-1}^{\Theta}, \\
P_{k \mid k}^{x}=\bar{P}_{k \mid k}^{x}+N_{k} \bar{P}_{k \mid k}^{\Theta} N_{k}^{T}, \\
P_{k \mid k}^{\Theta}=\bar{P}_{k \mid k}^{\Theta}, \\
P_{k \mid k}^{x \Theta}=N_{k} \bar{P}_{k \mid k}^{\Theta} .
\end{gathered}
$$

Considering characteristic of matrix $T(\cdot),(24)$ becomes

$$
\begin{gathered}
\bar{X}_{k \mid k-1}^{a}=T\left(-M_{k}\right) X_{k \mid k-1}^{a}, \\
\bar{P}_{k \mid k-1}=T\left(-M_{k}\right) P_{k \mid k-1} T\left(-M_{k}\right)^{T}, \\
\bar{X}_{k \mid k}^{a}=T\left(-N_{k}\right) X_{k \mid k}^{a}, \\
\bar{K}_{k}=T\left(-N_{k}\right) K_{k}, \\
\bar{P}_{k \mid k}=T\left(-N_{k}\right) P_{k \mid k} T\left(-N_{k}\right)^{T} .
\end{gathered}
$$

To obtain a full order filter and an augmented states filter, the following two-step iterative substitution method is used.

Step 1. Substituting (6)-(10) into (32), we have

$$
\begin{gathered}
\bar{X}_{k \mid k-1}^{a}=T\left(-M_{k}\right) \bar{A}_{k-1} X_{k-1 \mid k-1}^{a}+T\left(-M_{k}\right) \bar{B}_{k-1} U_{k-1}, \\
\bar{P}_{k \mid k-1}=\lambda_{k}\left(T\left(-M_{k}\right) \bar{F}_{k-1} P_{k-1 \mid k-1} \bar{F}_{k-1}^{T} T\left(-M_{k}\right)^{T}\right. \\
\left.+T\left(-M_{k}\right) Q_{k-1} T\left(-M_{k}\right)^{T}\right) \\
\bar{K}_{k}=T\left(-N_{k}\right) P_{k \mid k-1} \bar{H}_{k}^{T}\left(\bar{H}_{k} P_{k \mid k-1} \bar{H}_{k}^{T}+R_{k}\right)^{-1} \\
\bar{X}_{k \mid k}^{a}=T\left(-N_{k}\right)\left(X_{k \mid k-1}^{\alpha}+K_{k}\left(Y_{k}-\bar{C}_{k} X_{k \mid k-1}^{a}\right)\right), \\
\bar{P}_{k \mid k}=T\left(-N_{k}\right) P_{k \mid k-1} T\left(-N_{k}\right)^{T} \\
-T\left(-N_{k}\right) K_{k} \bar{H}_{k} P_{k \mid k-1} T\left(-N_{k}\right)^{T} .
\end{gathered}
$$

Step 2. Substituting (32) into the right-hand side of (33), the following equations are written:

$$
\begin{aligned}
& \bar{X}_{k \mid k-1}^{a}=T\left(-M_{k}\right) \bar{A}_{k-1} T\left(N_{k-1}\right) \bar{X}_{k-1 \mid k-1}^{a} \\
& +T\left(-M_{k}\right) \bar{B}_{k-1} U_{k-1} \text {, } \\
& \bar{P}_{k \mid k-1}=\lambda_{k}\left(T\left(-M_{k}\right) \bar{F}_{k-1} T\left(N_{k-1}\right) \bar{P}_{k-1 \mid k-1}\right. \\
& \times T\left(N_{k-1}\right)^{T} \bar{F}_{k-1}^{T} T\left(-M_{k}\right)^{T} \\
& \left.+T\left(-M_{k}\right) Q_{k-1} T\left(-M_{k}\right)^{T}\right), \\
& \bar{K}_{k}=T\left(M_{k}-N_{k}\right) \bar{P}_{k \mid k-1} T\left(M_{k}\right)^{T} \bar{H}_{k}^{T} \\
& \times\left(\bar{H}_{k} T\left(M_{k}\right) \bar{P}_{k \mid k-1} T\left(M_{k}\right)^{T} \bar{H}_{k}^{T}+R_{k}\right)^{-1}, \\
& \bar{X}_{k \mid k}^{a}=T\left(M_{k}-N_{k}\right) \bar{X}_{k \mid k-1}^{a}+\bar{K}_{k}\left(Y_{k}-\bar{C}_{k} T\left(M_{k}\right) \bar{X}_{k \mid k-1}^{a}\right) \text {, } \\
& \bar{P}_{k \mid k}=T\left(M_{k}-N_{k}\right) \bar{P}_{k \mid k-1} T\left(M_{k}-N_{k}\right)^{T} \\
& -\bar{K}_{k} \bar{H}_{k} T\left(M_{k}\right) \bar{P}_{k \mid k-1} T\left(M_{k}-N_{k}\right)^{T} \text {. } \\
& 0=\lambda_{k}\left(\bar{M}_{k} G_{k-1} \bar{P}_{k-1 \mid k-1}^{\Theta} G_{k-1}^{T}+Q_{k-1}^{x \Theta}\right. \\
& \left.-M_{k}\left(G_{k-1} \bar{P}_{k-1 \mid k-1}^{\Theta} G_{k-1}^{T}+Q_{k-1}^{\Theta}\right)\right), \\
& 0=M_{k}-N_{k}-\bar{K}_{k}^{x} S_{k},
\end{aligned}
$$

where

$$
\begin{gathered}
\bar{M}_{k}=\left(F_{k-1} N_{k-1}+E_{k-1}\right) G_{k-1}^{-1}, \\
S_{k}=H_{k}^{1} M_{k}+H_{k}^{2} .
\end{gathered}
$$

The above equations lead to

$$
\begin{gathered}
M_{k}=\bar{M}_{k}+\lambda_{k}\left(Q_{k}^{\varkappa \Theta}-\bar{M}_{k} Q_{k}^{\Theta}\right)\left(\bar{P}_{k \mid k-1}^{\Theta}\right)^{-1}, \\
N_{k}=M_{k}-\bar{K}_{k}^{x} S_{k} .
\end{gathered}
$$

Then, based on corresponding relationship in (34) (38), the ATEKF algorithm can be organized by the next two parts 
$[33,34]$. The first part of ATEKF for state and parameter prediction is as follows:

$$
\begin{gathered}
\bar{P}_{k \mid k-1}^{\Theta}=\lambda_{k}\left(G_{k-1} \bar{P}_{k-1 \mid k-1}^{\Theta} G_{k-1}^{T}+Q_{k-1}^{\Theta}\right), \\
E_{k}=\left.\frac{\partial}{\partial \Theta}\right|_{\bar{\Theta}_{k \mid k}}\left(A_{k}\left(\bar{X}_{k}+N_{k} \bar{\Theta}_{k}\right)+B_{k}^{\Theta} \Theta_{k}+B_{k}^{u} U_{k}\right), \\
\bar{M}_{k}=\left(F_{k-1} N_{k-1}+E_{k-1}\right)\left(G_{k-1}\right)^{-1}, \\
M_{k}=\bar{M}_{k}+\lambda_{k}\left(Q_{k-1}^{x \Theta}-\bar{M}_{k} Q_{k-1}^{\Theta}\right)\left(\bar{P}_{k \mid k-1}^{\Theta}\right)^{-1}, \\
\bar{Q}_{k}^{x}=Q_{k-1}^{x}-Q_{k-1}^{x \Theta} \bar{M}_{k}^{T}-M_{k}\left(Q_{k-1}^{x \Theta}-\bar{M}_{k} Q_{k-1}^{\Theta}\right)^{T}, \\
\bar{P}_{k \mid k-1}^{x}=\lambda_{k}\left(F_{k-1} \bar{P}_{k-1 \mid k-1}^{x} F_{k-1}^{T}+\bar{Q}_{k-1}^{x}\right), \\
\bar{\Theta}_{k \mid k-1}=G_{k-1} \bar{\Theta}_{k-1 \mid k-1}, \\
u_{k-1}=\left(A_{k-1} N_{k-1}+B_{k-1}^{\Theta}-M_{k} G_{k-1}\right) \bar{\Theta}_{k-1 \mid k-1}, \\
\bar{X}_{k \mid k-1}=A_{k-1} \bar{X}_{k-1 \mid k-1}+B_{k-1}^{u} U_{k-1}+u_{k-1}, \\
\bar{S}_{k}=C_{k} M_{k}, \\
S_{k}=H_{k}^{1} M_{k}+H_{k}^{2},
\end{gathered}
$$

with

$$
\begin{gathered}
V_{k}=H_{k}^{1} \bar{P}_{k-1 \mid k-1}^{x}\left(H_{k}^{1}\right)^{T}+\left(H_{k}^{1} N_{k-1}+H_{k}^{2}\right) \bar{P}_{k-1 \mid k-1}^{\Theta} \\
\times\left(H_{k}^{1} N_{k-1}+H_{k}^{2}\right)^{T}+R_{k}, \\
\eta_{k}=Y_{k}-C_{k} \bar{X}_{k \mid k-1}-\bar{S}_{k} \bar{\Theta}_{k \mid k-1}, \\
\bar{V}_{k}=\frac{1}{M-1} \sum_{i=k-M+1}^{k} \eta_{i} \eta_{i}^{T}, \\
\lambda_{k}=\max \left\{1, \frac{\operatorname{tr}\left(\bar{V}_{k}\right)}{\operatorname{tr}\left(V_{k}\right)}\right\} .
\end{gathered}
$$

The second part for state and parameter correction is as follows:

$$
\begin{gathered}
\bar{K}_{k}^{\Theta}=\bar{P}_{k \mid k-1}^{\Theta} S_{k}^{T}\left(H_{k}^{1} \bar{P}_{k \mid k-1}^{x}\left(H_{k}^{1}\right)^{T}+R_{k}+S_{k} \bar{P}_{k \mid k-1}^{\Theta} S_{k}^{T}\right)^{-1} \\
\bar{P}_{k \mid k}^{\Theta}=\bar{P}_{k \mid k-1}^{\Theta}-\bar{K}_{k}^{\Theta} S_{k} \bar{P}_{k \mid k-1}^{\Theta} \\
\bar{\Theta}_{k \mid k}=\bar{\Theta}_{k \mid k-1}+\bar{K}_{k}^{\Theta} \eta_{k}, \\
\bar{K}_{k}^{x}=\bar{P}_{k \mid k-1}^{x}\left(H_{k}^{1}\right)^{T}\left(H_{k}^{1} \bar{P}_{k \mid k-1}^{x}\left(H_{k}^{1}\right)^{T}+R_{k}\right)^{-1} \\
\bar{P}_{k \mid k}^{x}=\bar{P}_{k \mid k-1}^{x}-\bar{K}_{k}^{x} H_{k}^{1} \bar{P}_{k \mid k-1}^{x}, \\
\bar{X}_{k \mid k}=\bar{X}_{k \mid k-1}+\bar{K}_{k}^{x}\left(Y_{k}-C_{k} \bar{X}_{k \mid k-1}+\left(S_{k}-\bar{S}_{k}\right) \bar{\Theta}_{k \mid k-1}\right) \\
N_{k}=M_{k}-\bar{K}_{k}^{x} S_{k} .
\end{gathered}
$$

Using (26), the original state $\widehat{X}$ can be obtained by the sum of the state $\bar{X}$ with the augmented state $\bar{\Theta}$ :

$$
\begin{aligned}
\widehat{X}_{k \mid k-1} & =\bar{X}_{k \mid k-1}+M_{k} \bar{\Theta}_{k \mid k-1}, \\
\widehat{X}_{k \mid k} & =\bar{X}_{k \mid k}+N_{k} \bar{\Theta}_{k \mid k} .
\end{aligned}
$$

The initial conditions of this ATEKF are established with the initial conditions of the $\operatorname{AFEKF}\left(\widehat{X}_{0 \mid 0}, \widehat{\Theta}_{0 \mid 0}, P_{0 \mid 0}^{x}, P_{0 \mid 0}^{\Theta}, P_{0 \mid 0}^{x \Theta}\right)$, so that

$$
\begin{gathered}
N_{0}=P_{0 \mid 0}^{x \Theta}\left(P_{0 \mid 0}^{\Theta}\right)^{-1}, \quad \bar{X}_{0 \mid 0}=\widehat{X}_{0 \mid 0}-N_{0} \bar{\Theta}_{0 \mid 0}, \\
\bar{\Theta}_{0 \mid 0}=\widehat{\Theta}_{0 \mid 0}, \quad \bar{P}_{0 \mid 0}^{x}=P_{0 \mid 0}^{x}-N_{0} P_{0 \mid 0}^{\Theta} N_{0}^{T}, \\
\bar{P}_{0 \mid 0}^{\Theta}=P_{0 \mid 0}^{\Theta} .
\end{gathered}
$$

By using the number of arithmetic operations (multiplications and additions) as the measure of computational complexity, the computational advantage of the two-stage Kalman filter over the conventional Kalman Filter has been demonstrated in $[28,33]$. The analysis of computational complexity of ATEKF has rather similar process and does not need to be discussed here.

\subsection{The Stability Analysis of the ATEKF}

Theorem 1. The discrete-time adaptive fading extended Kalman filter ((6), (8), (9), (10), and (21)) is equivalent to the adaptive two-stage extended Kalman filter ((42) (62)).

Proof. Before proving the theorem, the following relationships are needed.

Using (42) and (45),

$$
\bar{M}_{k} G_{k-1} \bar{P}_{k-1 \mid k-1}^{\Theta} G_{k-1}^{T}=\frac{1}{\lambda_{k}} M_{k} \bar{P}_{k \mid k-1}^{\Theta}-Q_{k-1}^{x \Theta} .
$$

Using (54) and (57),

$$
\begin{gathered}
\bar{K}_{k}^{x} Z_{k}=\bar{P}_{k \mid k-1}^{x}\left(H_{k}^{1}\right)^{T}+\bar{K}_{k}^{x} S_{k} \bar{P}_{k \mid k-1}^{\Theta} S_{k}^{T}, \\
\bar{K}_{k}^{\Theta} Z_{k}=\bar{P}_{k \mid k-1}^{\Theta} S_{k}^{T},
\end{gathered}
$$

where

$$
\begin{aligned}
Z_{k}= & H_{k}^{1} \bar{P}_{k \mid k-1}^{x}\left(H_{k}^{1}\right)^{T}+H_{k}^{1} M_{k} \bar{P}_{k \mid k-1}^{\Theta} S_{k}^{T} \\
& +H_{k}^{2} \bar{P}_{k \mid k-1}^{\Theta} S_{k}^{T}+R_{k} .
\end{aligned}
$$

Using (55), (64), and (65),

$$
\begin{aligned}
\bar{P}_{k \mid k}^{\Theta} \bar{S}_{k}^{T}\left(\bar{K}_{k}^{x}\right)^{T} & =\left(\bar{P}_{k \mid k-1}^{\Theta} \bar{S}_{k}^{T}-\bar{K}_{k}^{\Theta} Z_{k}\right)\left(\bar{K}_{k}^{x}\right)^{T}+\bar{K}_{k}^{\Theta} H_{k}^{1} \bar{P}_{k \mid k-1}^{x} \\
& =\bar{K}_{k}^{\Theta} H_{k}^{1} \bar{P}_{k \mid k-1}^{x} .
\end{aligned}
$$

Assume that at time $k$, the estimated $\widehat{X}$ and $\widehat{\Theta}$ are, respectively, equal to the $X$ and $\Theta$. By recurrence reasoning, we show 
that the ATEKF is equivalent to the AFEKF because these properties are still true at time $k+1$ :

$$
\begin{gathered}
X_{k \mid k}=\widehat{X}_{k \mid k}, \quad \Theta_{k \mid k}=\widehat{\Theta}_{k \mid k}, \quad P_{k \mid k}^{x}=P_{k \mid k}^{11}, \\
P_{k \mid k}^{x \Theta}=P_{k \mid k}^{12}, \quad P_{k \mid k}^{\Theta}=P_{k \mid k}^{22},
\end{gathered}
$$

where $\left[\begin{array}{cc}P^{x} & P^{x \Theta} \\ \left(P^{x \Theta}\right)^{T} & P^{\ominus}\end{array}\right]$ and $\left[\begin{array}{cc}P^{11} & P^{12} \\ \left(P^{12}\right)^{T} & P^{22}\end{array}\right]$ represent the variancecovariance matrices of the system and estimated variables, respectively.

Using (6), (48) (50), (61), and (68), we obtain

$$
\begin{aligned}
X_{k \mid k-1}= & A_{k-1}\left(\bar{X}_{k-1 \mid k-1}+N_{k-1} \bar{\Theta}_{k-1 \mid k-1}\right) \\
& +B_{k-1}^{\Theta} \bar{\Theta}_{k-1 \mid k-1}+B_{k-1}^{u} U_{k-1} \\
= & \bar{X}_{k \mid k-1}-u_{k-1}+A_{k-1} N_{k-1} \bar{\Theta}_{k-1 \mid k-1} \\
& +B_{k-1}^{\Theta} \bar{\Theta}_{k-1 \mid k-1} \\
= & \bar{X}_{k \mid k-1}+M_{k} \bar{\Theta}_{k \mid k-1} \\
= & \widehat{X}_{k \mid k-1} .
\end{aligned}
$$

Using (6), (48), and (68), we obtain

$$
\Theta_{k \mid k-1}=G_{k-1} \Theta_{k-1 \mid k-1}=G_{k-1} \bar{\Theta}_{k-1 \mid k-1}=\bar{\Theta}_{k \mid k-1} .
$$

Using (21), (26) (28), (42), (43), and (45) (47), we obtain

$$
\begin{aligned}
& P_{k \mid k-1}^{x}=\lambda_{k}\left(F_{k-1} P_{k-1 \mid k-1}^{x} F_{k-1}^{T}\right. \\
&+E_{k-1} P_{k-1 \mid k-1}^{\Theta} E_{k-1}^{T}+F_{k-1} P_{k-1 \mid k-1}^{x \Theta} E_{k-1}^{T} \\
&\left.+E_{k-1}\left(P_{k-1 \mid k-1}^{x \Theta}\right)^{T} F_{k-1}^{T}+Q_{k-1}^{x}\right) \\
&=\lambda_{k}\left(F_{k-1} \bar{P}_{k-1 \mid k-1}^{x} F_{k-1}^{T}+Q_{k-1}^{x}\right. \\
& \quad+\left(F_{k-1} N_{k-1}+E_{k-1}\right) \bar{P}_{k-1 \mid k-1}^{\Theta} \\
&\left.\quad \times\left(F_{k-1} N_{k-1}+E_{k-1}\right)^{T}\right) \\
&=\bar{P}_{k \mid k-1}^{x}+M_{k} \bar{P}_{k \mid k-1}^{\Theta} M_{k}^{T} \\
&=\bar{P}_{k \mid k-1}^{x}=P_{k \mid k-1}^{11} .
\end{aligned}
$$

Using (21), (27), and (42), we obtain

$$
\begin{aligned}
P_{k \mid k-1}^{\Theta} & =\lambda_{k}\left(G_{k-1} P_{k-1 \mid k-1}^{\Theta} G_{k-1}^{T}+Q_{k-1}^{\Theta}\right) \\
& =\lambda_{k}\left(G_{k-1} \bar{P}_{k-1 \mid k-1}^{\Theta} G_{k-1}^{T}+Q_{k-1}^{\Theta}\right) \\
& =\bar{P}_{k \mid k-1}^{\Theta}=P_{k \mid k-1}^{22} .
\end{aligned}
$$

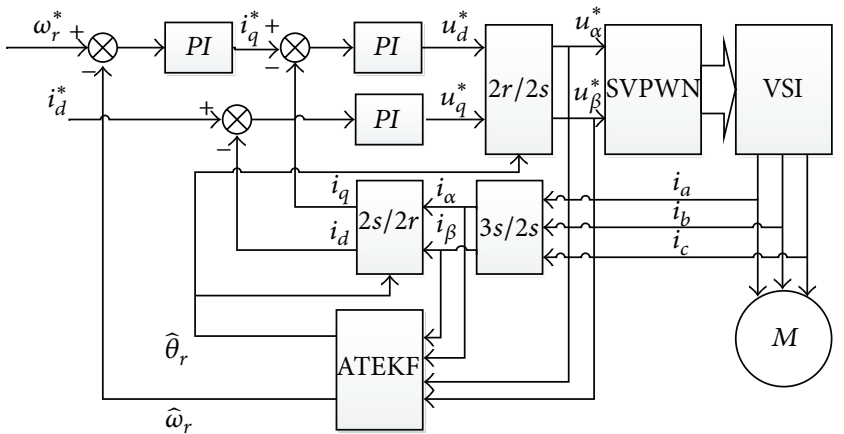

FIGURE 1: System diagram of the proposed ATEKF sensorless scheme.

Using (21), (28), (30), (31), and (44),

$$
\begin{aligned}
P_{k \mid k-1}^{x \Theta}= & \lambda_{k}\left(F_{k-1} P_{k-1 \mid k-1}^{x \Theta} G_{k-1}^{T}\right. \\
& \left.+E_{k-1} P_{k-1 \mid k-1}^{\Theta} G_{k-1}^{T}+Q_{k-1}^{x \Theta}\right) \\
= & \lambda_{k}\left(\left(F_{k-1} N_{k-1}+E_{k-1}\right) \bar{P}_{k-1 \mid k-1}^{\Theta} G_{k-1}^{T}+Q_{k-1}^{x \Theta}\right) \\
= & \lambda_{k}\left(\bar{M}_{k} G_{k-1} \bar{P}_{k-1 \mid k-1}^{\Theta} G_{k-1}^{T}+Q_{k-1}^{x \Theta}\right) \\
= & \bar{M}_{k} \bar{P}_{k \mid k-1}^{\Theta}=P_{k \mid k-1}^{12} .
\end{aligned}
$$

Using (10), (51), and (71) (73),

$$
\begin{aligned}
K_{k}^{x} & =\left(\bar{P}_{k \mid k-1}^{x}\left(H_{k}^{1}\right)^{T}+M_{k} \bar{P}_{k \mid k-1}^{\Theta} S_{k}^{T}\right) Z_{k}^{-1} \\
& =\left(\bar{P}_{k \mid k-1}^{x}\left(H_{k}^{1}\right)^{T}+\bar{K}_{k}^{x} S_{k} \bar{P}_{k \mid k-1}^{\Theta} S_{k}^{T}+N_{k} \bar{P}_{k \mid k-1}^{\Theta} S_{k}^{T}\right) Z_{k}^{-1} .
\end{aligned}
$$

Using (64), (65), and (74),

$$
K_{k}^{x}=\bar{K}_{k}^{x}+N_{k} \bar{K}_{k}^{\Theta} .
$$

Using (8), (51), (65), (72), and (73),

$$
\begin{aligned}
K_{k}^{\Theta} & =\left(\left(P_{k \mid k-1}^{x \Theta}\right)^{T}\left(H_{k}^{1}\right)^{T}+P_{k \mid k-1}^{\Theta}\left(H_{k}^{2}\right)^{T}\right) Z_{k}^{-1} \\
& =\bar{P}_{k \mid k-1}^{\Theta} S_{k}^{T} Z_{k}^{-1} \\
& =\bar{K}_{k}^{\Theta} .
\end{aligned}
$$

Using (9), (51), (56), (60), (61), (69), (70), and (75),

$$
\begin{aligned}
X_{k \mid k}= & X_{k \mid k-1}+K_{k}^{x} r_{k} \\
= & \bar{X}_{k \mid k-1}+\bar{K}_{k}^{x}\left(Y_{k}-C_{k} \bar{X}_{k \mid k-1}\right) \\
& +\left(M_{k}-\bar{K}_{k}^{x} \bar{S}_{k}\right) \bar{\Theta}_{k \mid k-1}+N_{k} \bar{K}_{k}^{\Theta} r_{k}
\end{aligned}
$$




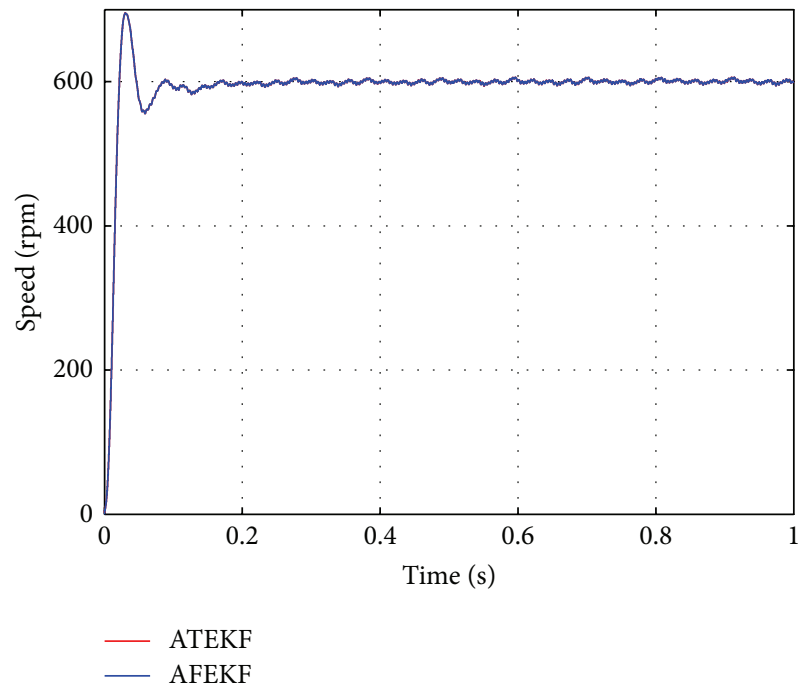

(a) Speed estimation

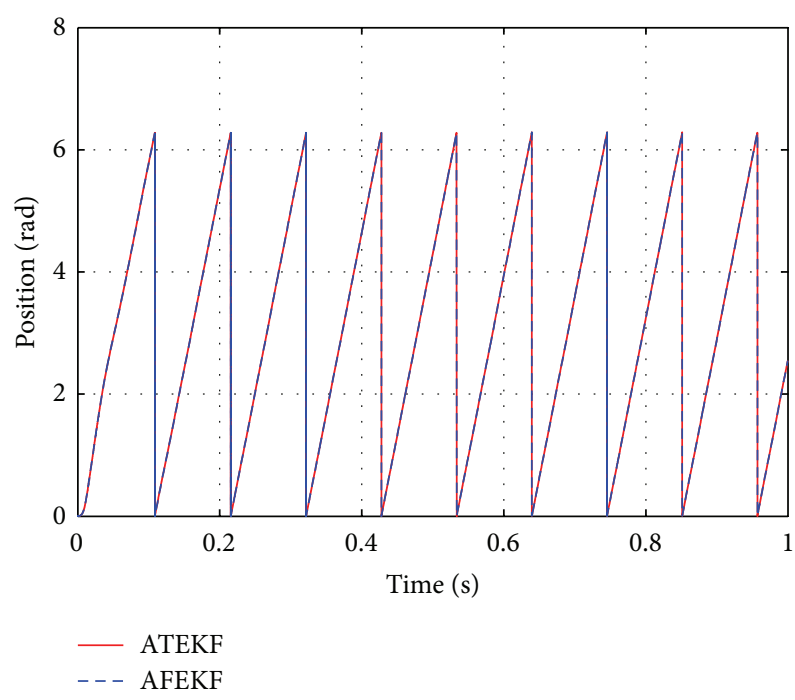

(c) Position estimation

(d) Difference of position estimation

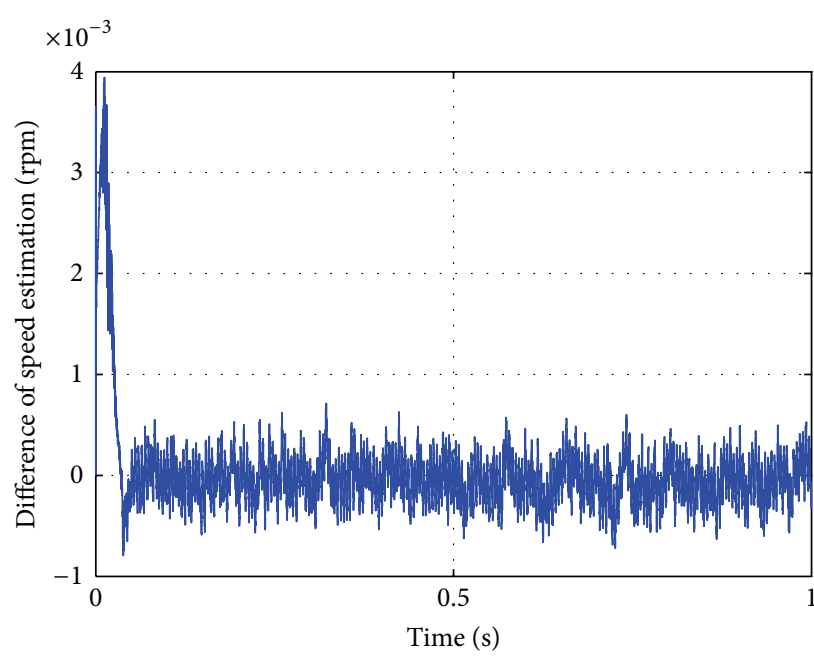

(b) Difference of speed estimation

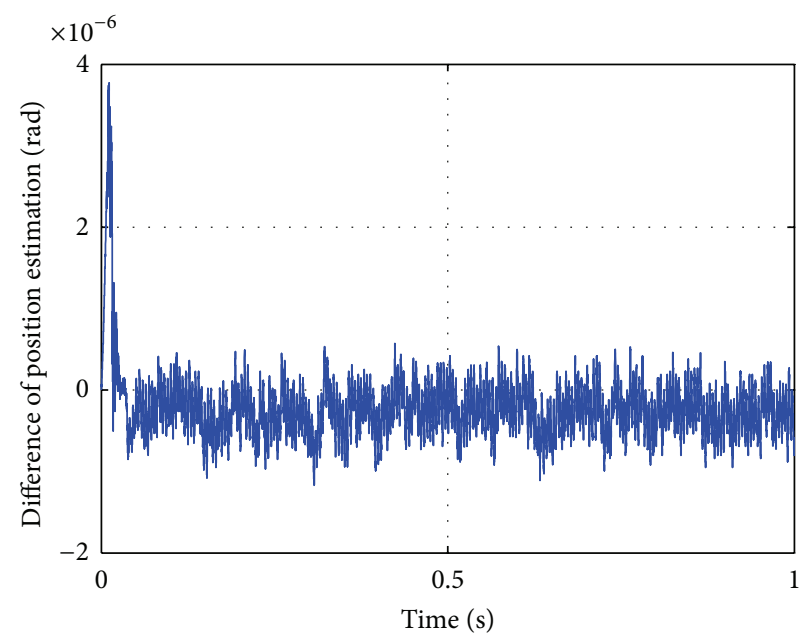

FIGURE 2: Experimental results for speed and position estimation (ATEKF and AFEKF).

$$
\begin{aligned}
& =\bar{X}_{k \mid k}+N_{k} \bar{\Theta}_{k \mid k} \\
& =\widehat{X}_{k \mid k},
\end{aligned}
$$

where

$$
\begin{aligned}
r_{k} & =Y_{k}-\bar{C}_{k} X_{k \mid k-1}^{a} \\
& =Y_{k}-C_{k} \bar{X}_{k \mid k-1}-\bar{S}_{k} \bar{\Theta}_{k \mid k-1} .
\end{aligned}
$$

Using (9), (70), (76), and (78),

$$
\begin{aligned}
\Theta_{k \mid k} & =\Theta_{k \mid k-1}+K_{k}^{\Theta} r_{k} \\
& =\bar{\Theta}_{k \mid k-1}+\bar{K}_{k}^{\Theta} r_{k}=\bar{\Theta}_{k \mid k} .
\end{aligned}
$$

Using (10), (29), (47), (51),(55), (60), (71), and (75),

$$
\begin{aligned}
P_{k \mid k}^{x}= & P_{k \mid k-1}^{x}-K_{k}^{x}\left(H_{k}^{1} P_{k \mid k-1}^{x}+H_{k}^{2}\left(P_{k \mid k-1}^{x \Theta}\right)^{T}\right) \\
= & \bar{P}_{k \mid k-1}^{x}+M_{k} \bar{P}_{k \mid k-1}^{\Theta} M_{k}^{T}-\left(\bar{K}_{k}^{x}+N_{k} \bar{K}_{k}^{\Theta}\right) \\
& \times\left(H_{k}^{1} \bar{P}_{k \mid k-1}^{x}+S_{k} \bar{P}_{k \mid k-1}^{\Theta} M_{k}^{T}\right) \\
= & \bar{P}_{k \mid k-1}^{x}+\bar{K}_{k}^{x} H_{k}^{1} \bar{P}_{k \mid k-1}^{x} \\
& +N_{k}\left(\bar{P}_{k \mid k-1}^{\Theta} M_{k}^{T}-\bar{K}_{k}^{\Theta} S_{k} \bar{P}_{k \mid k-1}^{\Theta} M_{k}^{T}-\bar{K}_{k}^{\Theta} H_{k}^{1} \bar{P}_{k \mid k-1}^{x}\right) \\
= & \bar{P}_{k \mid k}^{x}+N_{k}\left(\bar{P}_{k \mid k}^{\Theta} M_{k}^{T}-\bar{K}_{k}^{\Theta} H_{k}^{1} \bar{P}_{k \mid k-1}^{x}\right) \\
= & \bar{P}_{k \mid k}^{x}+N_{k} \bar{P}_{k \mid k}^{\Theta} N_{k}^{T} .
\end{aligned}
$$




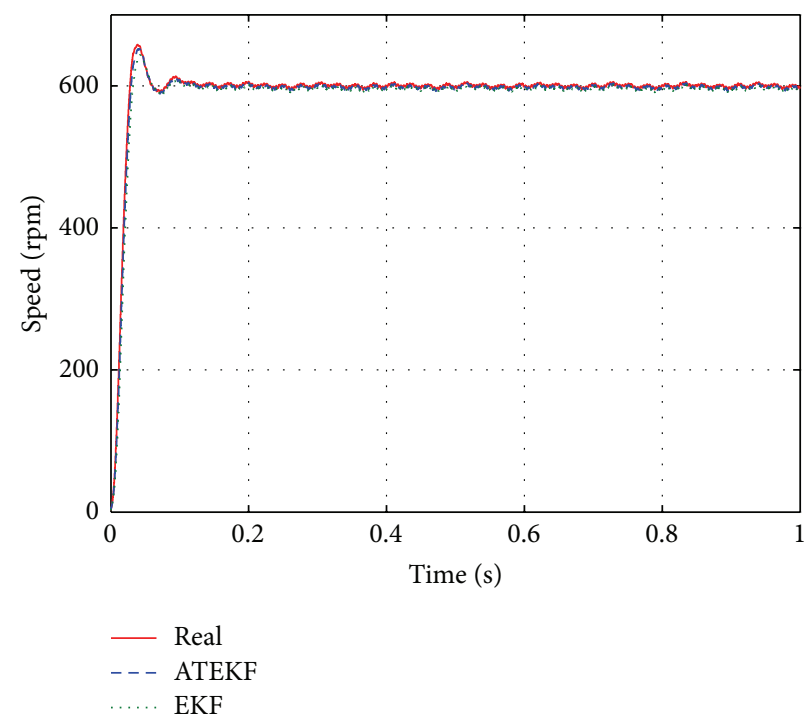

(a) Speed estimation

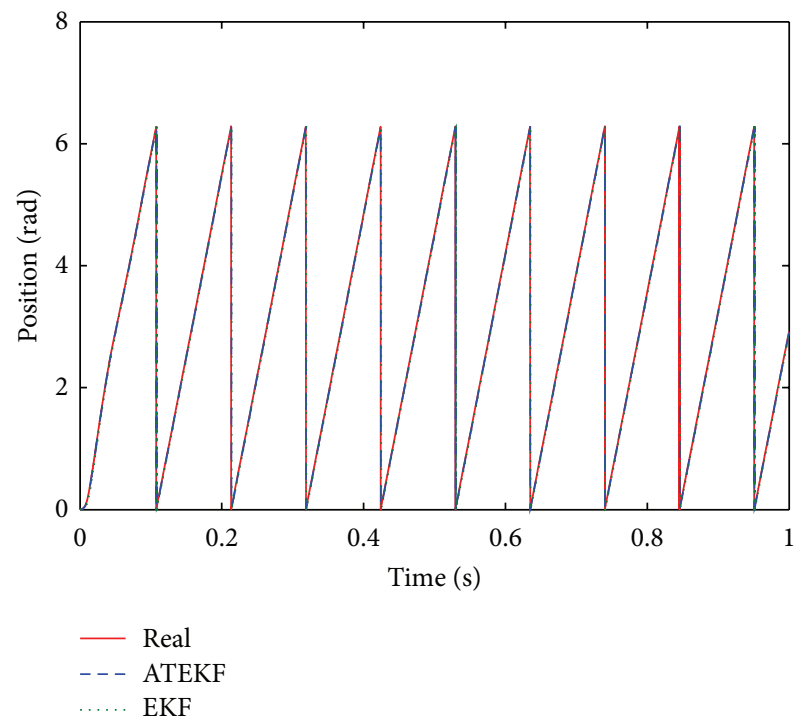

(c) Position estimation

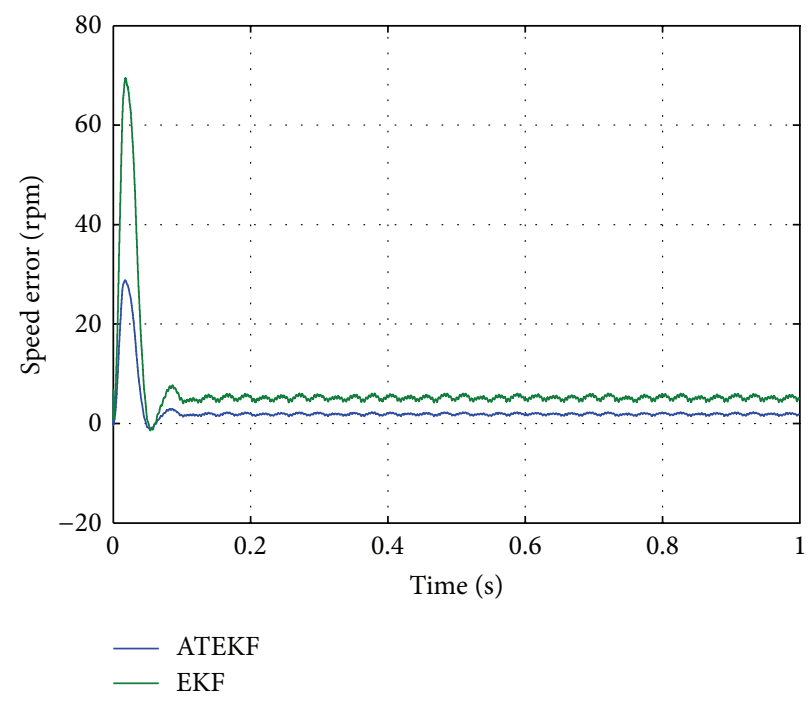

(b) Speed error

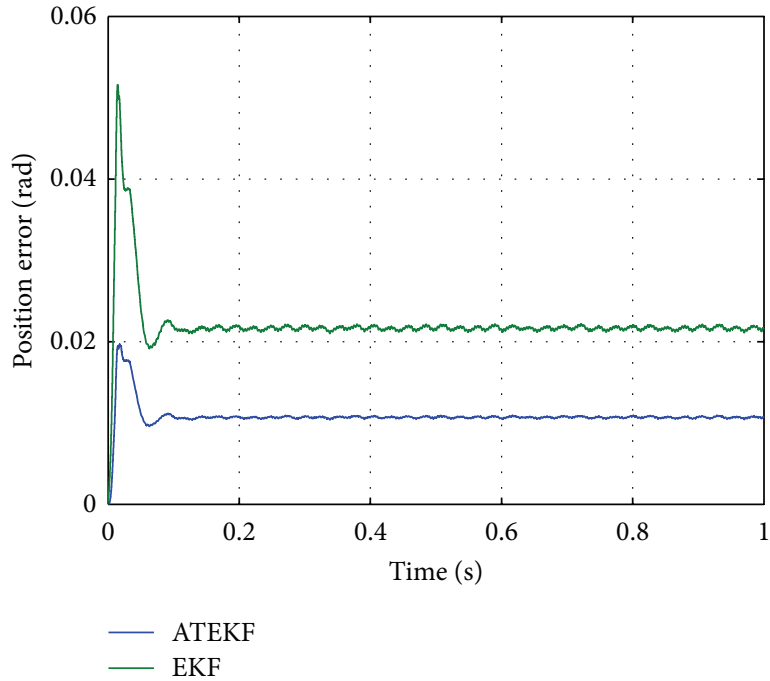

(d) Position error

FIGURE 3: Experimental results with step change of speed reference.

Using (10), (31), (51), (55), (58), (60), (71), and (72),

$$
\begin{aligned}
P_{k \mid k}^{x \Theta} & =P_{k \mid k-1}^{x \Theta}-K_{k}^{x}\left(H_{k}^{1} P_{k \mid k-1}^{x \Theta}+H_{k}^{2} P_{k \mid k-1}^{\Theta}\right) \\
& =\left(M_{k}-\bar{K}_{k}^{x} S_{k}-N_{k} \bar{K}_{k}^{\Theta} S_{k}\right) \bar{P}_{k \mid k-1}^{\Theta} \\
& =N_{k} \bar{P}_{k \mid k}^{\Theta} .
\end{aligned}
$$

Using (10), (30), (51), (55), (58), (72), (73), and (76),

$$
\begin{aligned}
P_{k \mid k}^{x} & =P_{k \mid k-1}^{\Theta}-K_{k}^{\Theta}\left(H_{k}^{1} P_{k \mid k-1}^{x \Theta}+H_{k}^{2}\left(P_{k \mid k-1}^{\Theta}\right)^{T}\right) \\
& =\bar{P}_{k \mid k-1}^{\Theta}-\bar{K}_{k}^{\Theta} S_{k} \bar{P}_{k \mid k-1}^{\Theta} \\
& =\bar{P}_{k \mid k-1}^{\Theta} .
\end{aligned}
$$

Finally, show that (68) holds at time $k=0$. This can be verified by the initial parameters in (62).

\section{Experimental Results}

The experiment of this paper aims at making a comparison among ATEKF, AFEKF, and EKF to verify validity and feasibility of ATEKF algorithm. The proposed PMSM sensorless control strategy based on ATEKF is shown in Figure 1. The drive system consists of a three-phase, eight-pole, $1.2 \mathrm{~kW}$ PMSM, driven from a three-phase insulated gate bipolar transistor (IGBT) inverter. The PMSM is mechanically coupled to a magnetic clutch, which provides rated torque, even at very low speeds. The drive system is implemented by an Expert3 control system of Myway company. The core DSP processor in Expert3 control system is TMS320C6713 


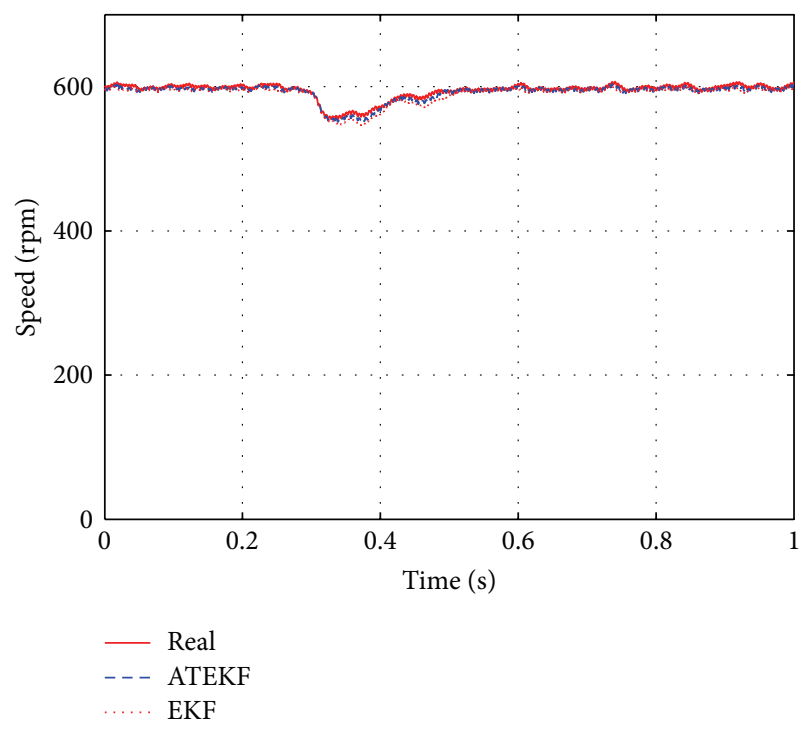

(a) Speed estimation

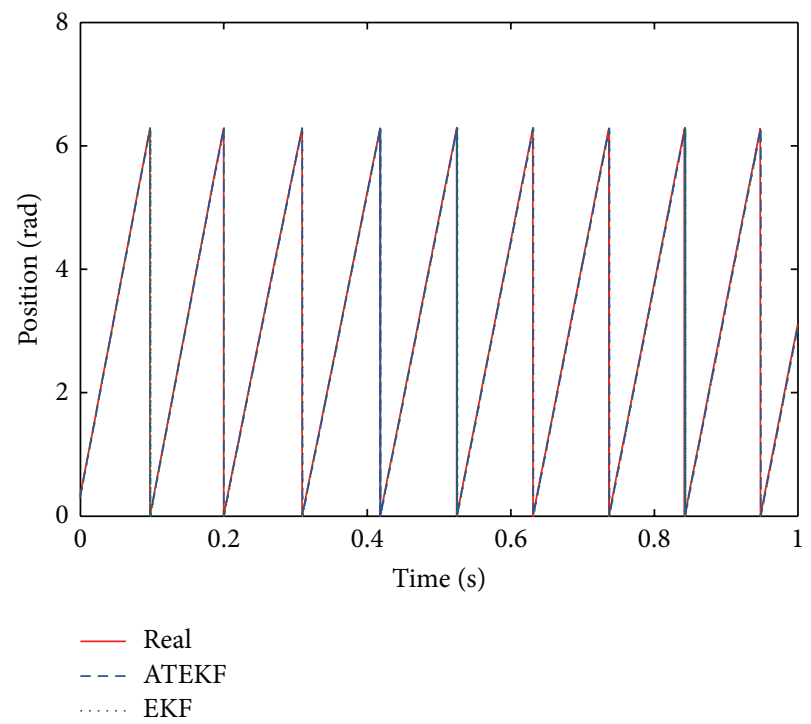

(c) Position estimation

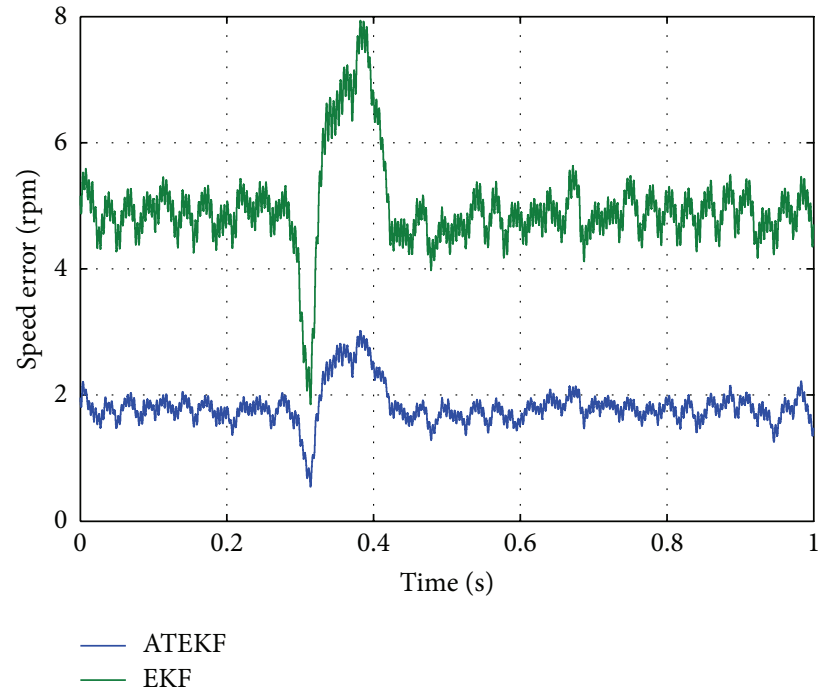

(b) Speed error

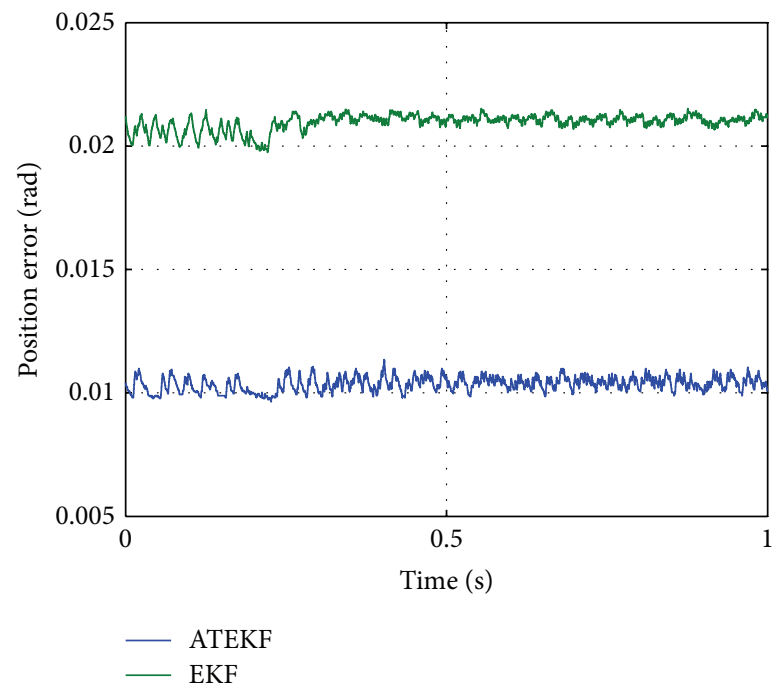

(d) Position error

FIGURE 4: Experimental results with step change of load torque.

with a clock speed of $225 \mathrm{MHz}$. The actual rotor position and speed are obtained from an incremental encoder with 10000 pulses per revolution. The inverter space-vector PWM control, current regulator, and observer algorithm operate with a $100 \mu$ s sampling/integration time step. The currents flowing in the stator windings are measured with two hall effect current sensors. The parameters of the PMSM are shown in Table 1.

In the experiments, real-time parameter estimations observed by ATEKF are used to formulate the closed loop, such as rotor speed and position. The estimations obtained by conventional EKF or AFEKF are not included in the sensorless FOC and only evaluated in open loop.

Experiment 1 (equivalence between AFEKF and ATEKF). In this experiment, a comparison is made to verify the
TABLE 1: PMSM prototype specification.

\begin{tabular}{lc}
\hline Quantity & Value \\
\hline Nominal torque & $4 \mathrm{Nm}$ \\
Nominal speed & $3000 \mathrm{rpm}$ \\
Stator resistance $R_{s}$ & $0.525 \Omega$ \\
$d$ axes inductances $L_{d}$ & $1.65 \mathrm{mH}$ \\
$q$ axes inductances $L_{q}$ & $1.65 \mathrm{mH}$ \\
PM Flux linkage $\psi_{f}$ & $0.0744 \mathrm{~Wb}$ \\
Rotor inertia & $0.54 \times 10^{-3} \mathrm{~kg} \cdot \mathrm{m}^{2}$ \\
Poles pairs & 4 \\
\hline
\end{tabular}

equivalence between AFEKF and ATEKF. The machine is accelerated from $0 \mathrm{rpm}$ to $600 \mathrm{rpm}$ at $0 \mathrm{~s}$ and the torque load is set to $2 \mathrm{Nm}$. The results are shown in Figure 2 . 


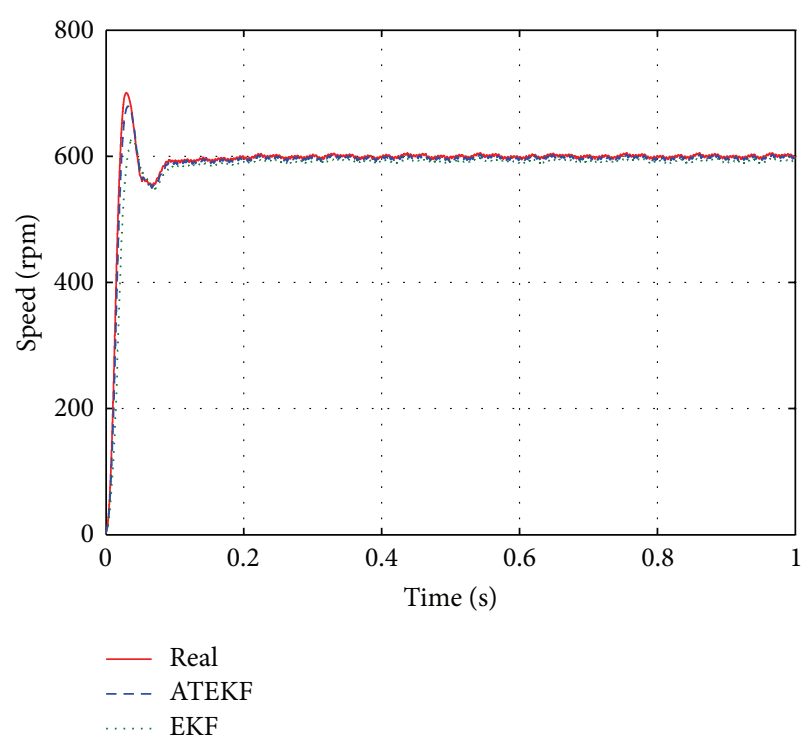

(a) Speed estimation

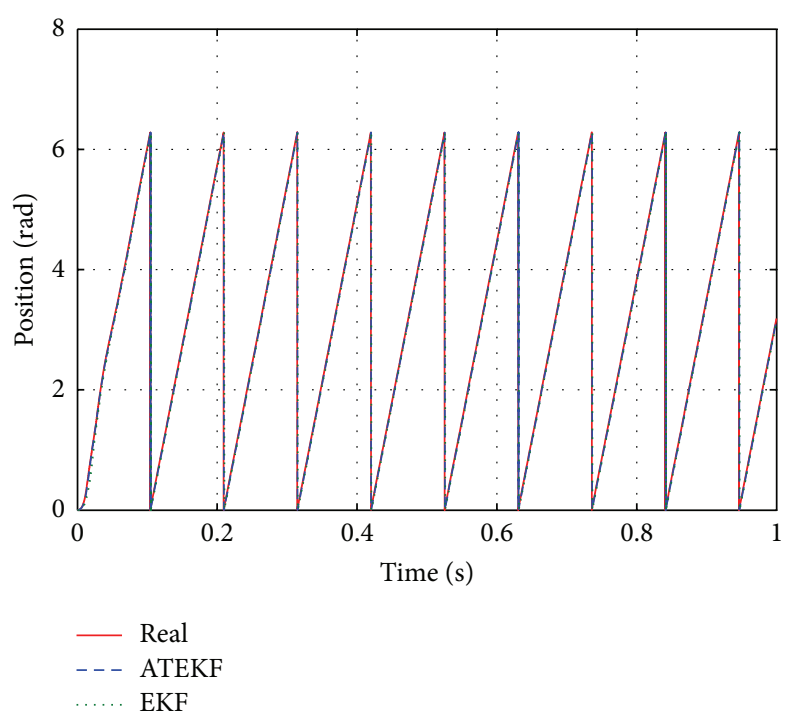

(c) Position estimation

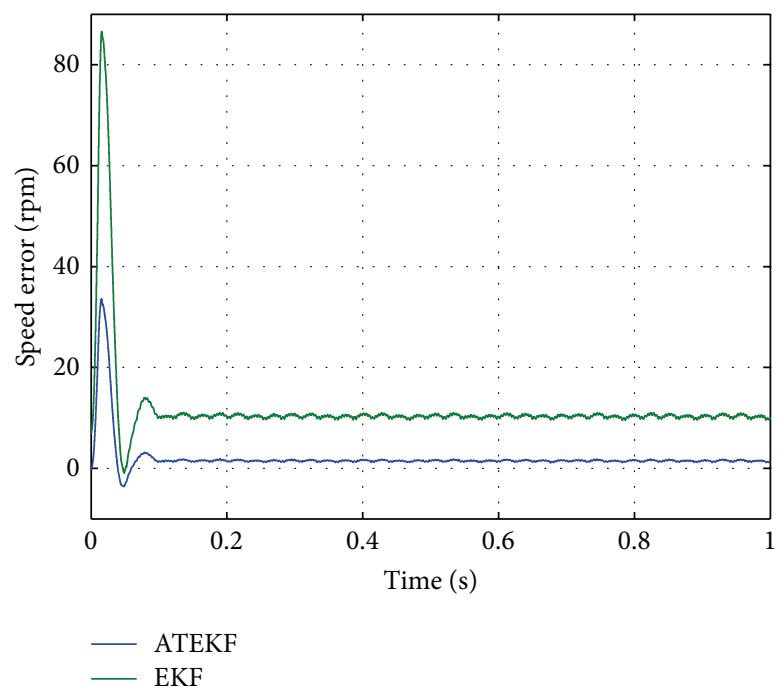

(b) Speed error

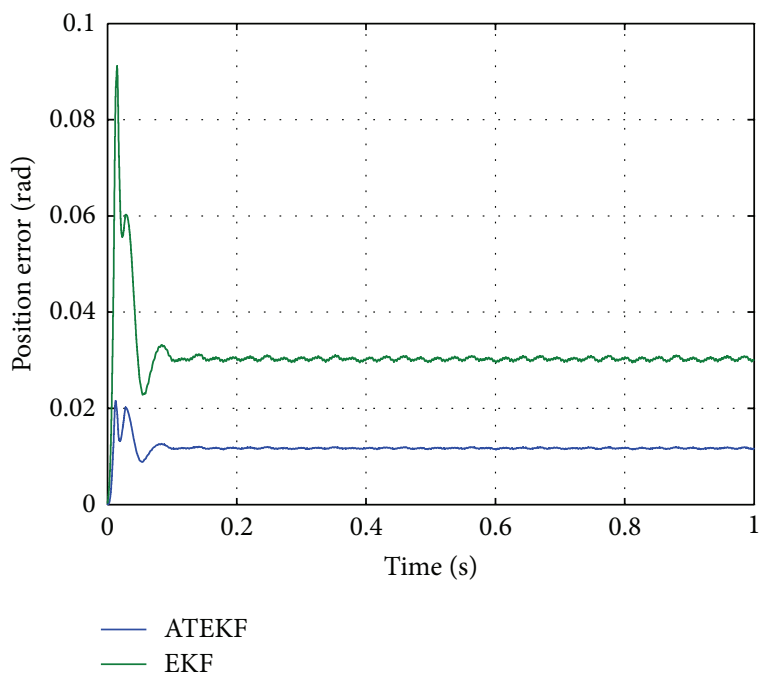

(d) Position error

FIgURE 5: Experimental results with parameter variation.

During the transient, the maximum difference in speed and position measured by the two estimators is $0.0039 \mathrm{rpm}$ and $0.0000037 \mathrm{rad}$, respectively. When PMSM reaches the given speed, the difference is rather null as we can see in Figure 2. Due to limited computer word, the differences can be seen as finite-word-length errors caused by single-precision arithmetic used in $\mathrm{C}$ code. These experimental results demonstrate that the two observers are mathematically equivalent.

Experiment 2 (dynamics in speed step). From Experiment 2 to Experiment 4, a comparison is made between ATEKF and EKF to verify the performance of the former.

The machine is accelerated from $0 \mathrm{rpm}$ to $600 \mathrm{rpm}$ at $0 \mathrm{~s}$ and the torque load is set to $2 \mathrm{Nm}$. Figures $3(\mathrm{a})$ and $3(\mathrm{c})$ show that ATEKF gets better dynamic speed response performance than EKF when PMSM is at the stage of start-up towards expected speed command. Figures $3(\mathrm{~b})$ and $3(\mathrm{~d})$ show the speed and position error in the ATEKF and the EKF for the sensorless control system. As expected, the steady errors of the ATEKF are smaller than those of the EKF.

Experiment 3 (dynamics in load-torque steps). Figure 4 shows the dynamic response of the sensorless drive with a load disturbance. The load torque varies from $2 \mathrm{Nm}$ to $4 \mathrm{Nm}$, at a constant speed of $600 \mathrm{rpm}$. In response to disturbance acting in the electrical system, the actual velocity deviates significantly from the reference. It should be remarked that when the load changes, the speed response with ATEKFbased observer is faster than the one with EKF-based observer.

Experiment 4 (dynamics in parameter mismatch). In order to further verify the robustness against model-plant parameter mismatches of the ATEKF, the change in stator resistance 
is considered. When the motor is running, stator resistance increases due to temperature. To simulate this condition, the stator resistances in ATEKF and EKF module are reduced to $80 \%$. This is equivalent to the stator resistances which increased to $125 \%$ in PMSM. The machine is still accelerated from $0 \mathrm{rpm}$ to $600 \mathrm{rpm}$ at $0 \mathrm{~s}$ and the torque load is set to $2 \mathrm{Nm}$.

It is obvious that the motor speed and position observed by ATEKF can track their real value faster than EKF during the transient. A comparison is made between results of Experiments 2 and 4. Compared to Figure 3, Figure 5 shows that the increases in dynamic and steady errors of the ATEKF are obviously smaller than those of the EKF. This means that the performance, which results from the conventional EKF, is influenced heavily by increase in uncertainty, while in the proposed ATEKF the influence of the uncertainty is very small. Good robustness of ATEKF is verified.

The experimental results show that the ATEKF has strong robustness against model-plant parameter mismatches and good real-time state tracking ability.

\section{Conclusion}

To obtain satisfactory tracking results of EKF, the designers are required to have good knowledge about both the dynamic process and measurement models. Moreover, the real-time digital implementation of extended Kalman filters algorithm for sensorless FOC requires a very fast signal processor to perform complex mathematical calculation. The above demands are widely regarded as main limitations to apply EKF to PMSMs in the industrial field. So this paper proposes a novel extended Kalman filter called adaptive two-stage extended Kalman filter, which has the characteristics of both AFEKF and TSEKF. To design the ATEKF, the AFEKF is firstly designed. Then AFEKF is decoupled into two parallel filters to formulate ATEKF. Experimental results verified the robustness and strong tracking ability of ATEKF. On the other hand, the ATEKF algorithm provides a new idea to solve computational complexity and allows us to use cheaper DSP in practical application.

\section{Acknowledgment}

This work is supported by the National Natural Science Foundation of China under Grant no. 51377058.

\section{References}

[1] B. K. Bose, Power Electronics and Variable Frequency DrivesTechnology and Application, IEEE Press, New York, NY, USA, 1997.

[2] X. Yue, D. M. Vilathgamuwa, and K.-J. Tseng, "Observer-based robust adaptive control of PMSM with initial rotor position uncertainty," IEEE Transactions on Industry Applications, vol. 39, no. 3, pp. 645-656, 2003.

[3] Y.-S. Kung and M.-H. Tsai, "FPGA-based speed control IC for PMSM drive with adaptive fuzzy control," IEEE Transactions on Power Electronics, vol. 22, no. 6, pp. 2476-2486, 2007.

[4] Y. A.-R. I. Mohamed, "Design and implementation of a robust current-control scheme for a PMSM vector drive with a simple adaptive disturbance observer," IEEE Transactions on Industrial Electronics, vol. 54, no. 4, pp. 1981-1988, 2007.

[5] K. Jezernik, J. Korelic, and R. Horvat, "PMSM sliding mode FPGA-based control for torque ripple reduction," IEEE Transactions on Power Electronics, vol. 28, no. 7, pp. 3549-3556, 2013.

[6] J. Solsona, M. Valla, and C. Muravchik, "Nonlinear control of a permanent magnet synchronous motor with disturbance torque estimation," IEEE Transactions on Energy Conversion, vol. 15, no. 2, pp. 163-168, 2000.

[7] S. Li and H. Gu, "Fuzzy adaptive internal model control schemes for PMSM speed-regulation system," IEEE Transactions on Industrial Informatics, vol. 8, no. 4, pp. 767-779, 2012.

[8] E. Kim and S. Lee, "Output feedback tracking control of MIMO systems using a fuzzy disturbance observer and its application to the speed control of a PM synchronous motor," IEEE Transactions on Fuzzy Systems, vol. 13, no. 6, pp. 725-741, 2005.

[9] S. Li and Z. Liu, "Adaptive speed control for permanent-magnet synchronous motor system with variations of load inertia," IEEE Transactions on Industrial Electronics, vol. 56, no. 8, pp. 30503059, 2009.

[10] H. Liu and S. Li, "Speed control for PMSM servo system using predictive functional control and extended state observer," IEEE Transactions on Industrial Electronics, vol. 59, no. 2, pp. 11711183, 2012.

[11] V. Q. Leu, H. H. Choi, and J.-W. Jung, "Fuzzy sliding mode speed controller for PM synchronous motors with a load torque observer," IEEE Transactions on Power Electronics, vol. 27, no. 3, pp. 1530-1539, 2012.

[12] A. K. Abdelsalam, M. I. Masoud, M. S. Hamad, and B. W. Williams, "Improved sensorless operation of a CSI-based induction motor drive: long feeder ase," IEEE Transactions on Power Electronics, vol. 28, no. 8, pp. 4001-4012, 2013.

[13] G. Wang, Z. Li, G. Zhang, Y. Yu, and D. Xu, "Quadrature PLLbased high-order sliding-mode observer for IPMSM sensorless control with online MTPA control strategy," IEEE Transactions on Energy Conversion, vol. 28, no. 1, pp. 214-224, 2013.

[14] T. J. Vyncke, R. K. Boel, and J. A. A. Melkebeek, "On the stator flux linkage estimation of an PMSM with extended Kalman filters," in Proceedings of the 5th IET International Conference on Power Electronics, Machines and Drives (PEMD '10), pp. 19-21, April 2010.

[15] G. Foo, S. Sayeef, and M. F. Rahman, "SVM direct torque controlled interior permanent magnet synchronous motor drive using an extended Kalman filter," in Proceedings of the 4th IET International Conference on Power Electronics, Machines and Drives (PEMD '08), pp. 712-716, April 2008.

[16] M. Barut and R. Demir, "Bi input-extended Kalman filter based speed-sensorless direct torque control of IMs," in Proceedings of the 19th International Conference on Electrical Machines (ICEM '10), pp. 1-5, September 2010.

[17] I. M. Alsofyani, N. Idris, T. Sutikno, and Y. A. Alamri, "An optimized Extended Kalman Filter for speed sensorless direct troque control of an induction motor," in Proceedings of the IEEE International Conference on Power and Energy (PECON '12), pp. 319-324, 2012.

[18] D.-J. Jwo and S.-H. Wang, "Adaptive fuzzy strong tracking extended Kalman filtering for GPS navigation," IEEE Sensors Journal, vol. 7, no. 5, pp. 778-789, 2007.

[19] D. H. Zhou and P. M. Frank, "Strong tracking filtering of nonlinear time-varying stochastic systems with coloured noise: 
application to parameter estimation and empirical robustness analysis," International Journal of Control, vol. 65, no. 2, pp. 295307, 1996.

[20] R. K. Mehra, "On the identification of variances and adaptive Kalman filtering," IEEE Transactions on Automatic Control, vol. 15, no. 2, pp. 175-184, 1970.

[21] D. Loebis, R. Sutton, J. Chudley, and W. Naeem, "Adaptive tuning of a Kalman filter via fuzzy logic for an intelligent AUV navigation system," Control Engineering Practice, vol. 12, no. 12, pp. 1531-1539, 2004.

[22] A. Chatterjee and F. Matsuno, "A neuro-fuzzy assisted extended Kalman filter-based approach for simultaneous localization and mapping (SLAM) problems," IEEE Transactions on Fuzzy Systems, vol. 15, no. 5, pp. 984-997, 2007.

[23] L. Ozbek and M. Efe, "An adaptive Extended Kalman Filter with application to compartment models," Communications in Statistics B, vol. 33, no. 1, pp. 145-158, 2004.

[24] B. Friedland, "Treatment of bias in recursive filtering," IEEE Transactions on Automatic Control, vol. 14, no. 4, pp. 359-367, 1969.

[25] M. B. Ignagni, "An alternate derivation and extension of Friedland's two-stage Kalman estimator," IEEE Transactions on Automatic Control, vol. 26, no. 3, pp. 746-750, 1981.

[26] J. M. Mendel and H. D. Washburn, "Multistage estimation of bias states in linear systems," International Journal of Control, vol. 28, no. 4, pp. 511-524, 1978.

[27] A. T. Alouani, P. Xia, T. R. Rice, and W. D. Blair, "On the optimality of two-stage state estimation in the presence of random bias," IEEE Transactions on Automatic Control, vol. 38, no. 8, pp. 1279-1282, 1993.

[28] C.-S. Hsieh and F.-C. Chen, "Optimal solution of the two-stage Kalman estimator," IEEE Transactions on Automatic Control, vol. 44, no. 1, pp. 194-199, 1999.

[29] D. H. Zhou, Y. X. Sun, Y. G. Xi, and Z. J. Zhang, "Extension of Friedland's separate-bias estimation to randomly time-varying bias of nonlinear systems," IEEE Transactions on Automatic Control, vol. 38, no. 8, pp. 1270-1273, 1993.

[30] C.-S. Hsieh, “General two-stage extended Kalman filters," IEEE Transactions on Automatic Control, vol. 48, no. 2, pp. 289-293, 2003.

[31] A. Shademan and F. J. Sharifi, "Sensitivity analysis of EKF and iterated EKF pose estimation for position-based visual servoing," in Proceedings of the IEEE Conference on Control Applications (CCA '05), pp. 755-760, 2005.

[32] K. H. Kim, J. G. Lee, and C. G. Park, "Adaptive two-stage extended Kalman filter for a fault-tolerant INS-GPS loosely coupled system," IEEE Transactions on Aerospace and Electronic Systems, vol. 45, no. 1, pp. 125-137, 2009.

[33] M. Hilairet, F. Auger, and E. Berthelot, "Speed and rotor flux estimation of induction machines using a two-stage extended Kalman filter," Automatica, vol. 45, no. 8, pp. 1819-1827, 2009.

[34] A. Akrad, M. Hilairet, and D. Diallo, "A sensorless PMSM drive using a two stage extended Kalman estimator," in Proceedings of the 34th Annual Conference of the IEEE Industrial Electronics Society (IECON '08), pp. 2776-2781, November 2008. 


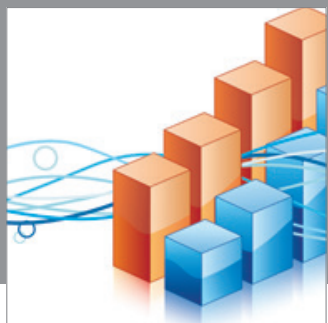

Advances in

Operations Research

mansans

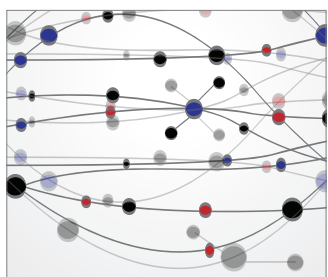

The Scientific World Journal
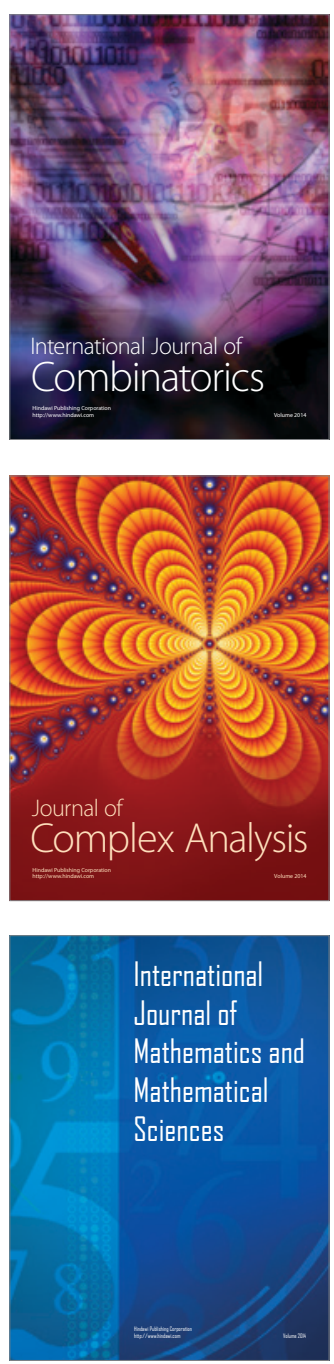
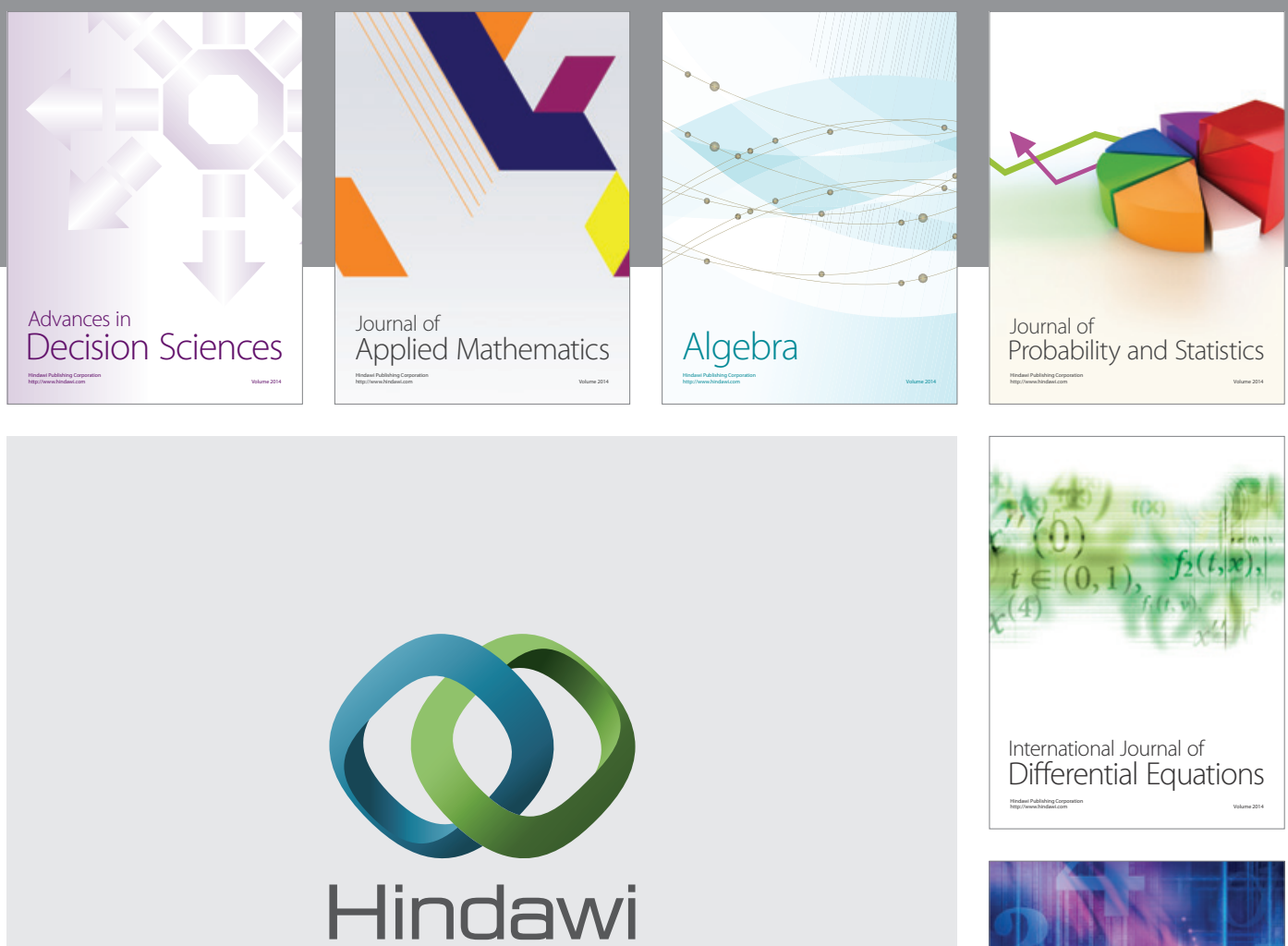

Submit your manuscripts at http://www.hindawi.com
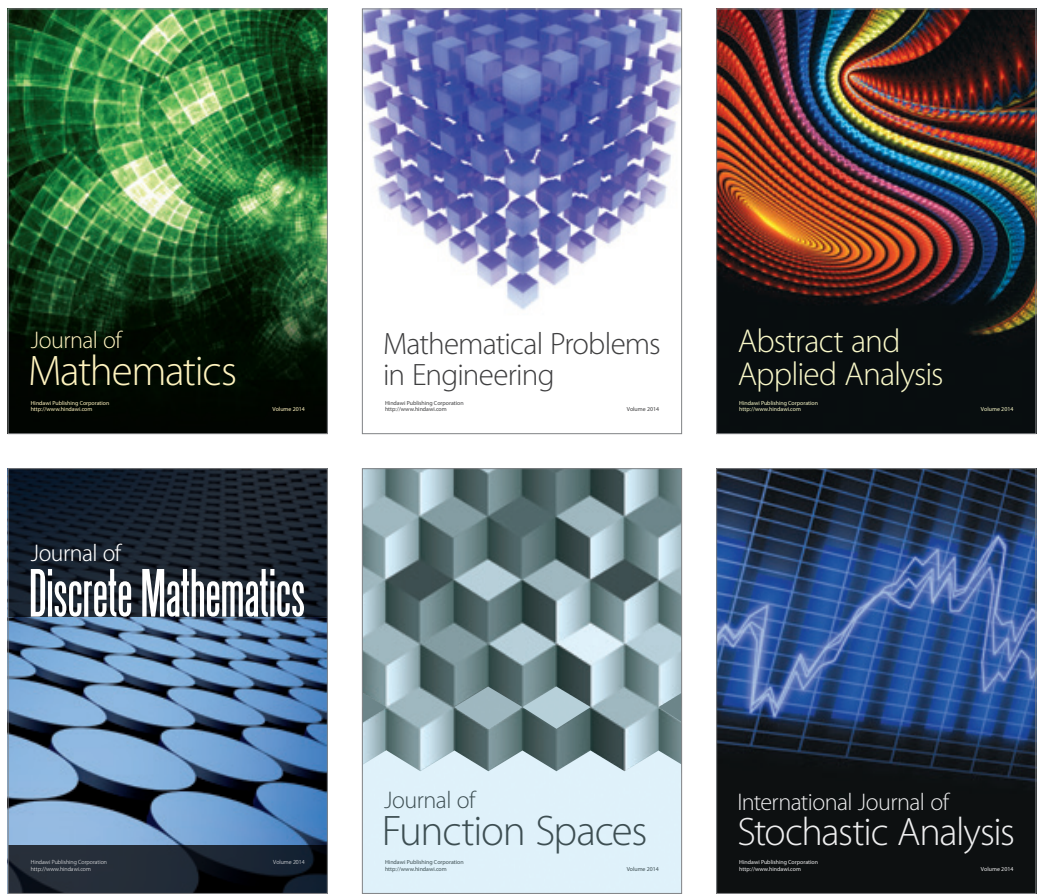

Journal of

Function Spaces

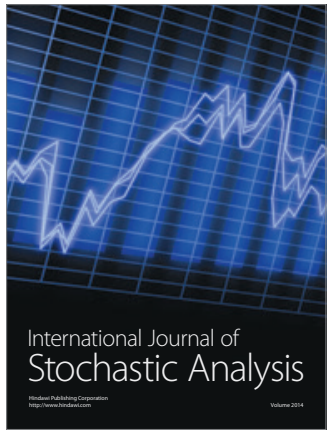

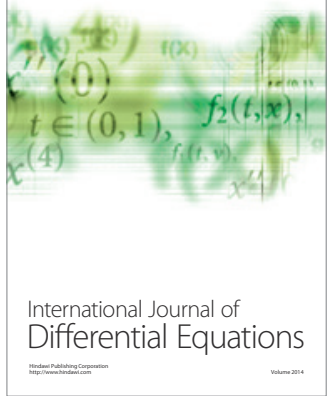
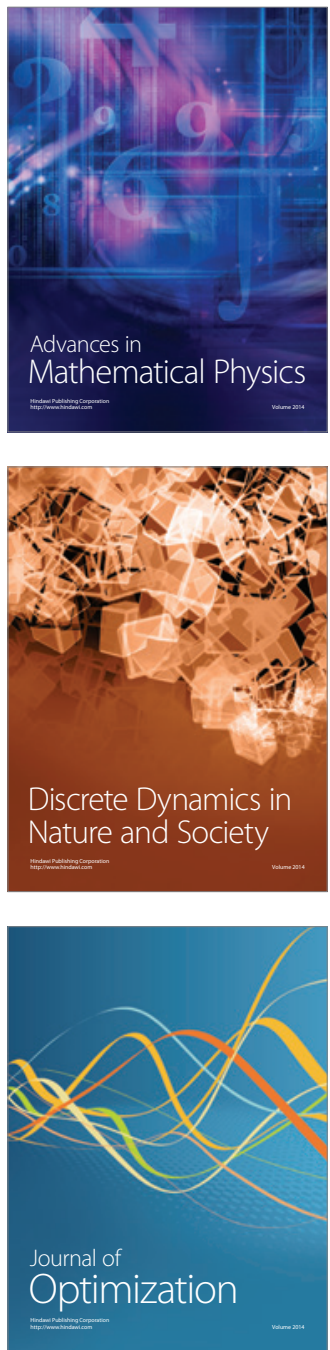